\title{
Artículo
}

\section{Oraciones completivas de sustantivo en español y portugués: ¿infinitivo u oración finita?} Nominal complement clauses in Spanish and Portuguese: infinitival clauses or finite clauses?

\author{
Anton Granvik \\ Universidad de Gotemburgo, Suecia \\ anton.granvik@sprak.gu.se
}

Original recibido: 2016/07/29

Dictamen enviado al autor: 2016/10/25

Aceptado: 2016/10/25

\section{Abstract}

This paper focuses on two types of nominal complement clauses, namely finite (el hecho de que vaya 'the fact that s/he goes') and infinitival complements (el hecho de ir 'the fact of going'). The aim is to determine whether the two complement types are "functionally identical" (cf. Bogard \& Company 1989). The analysis of two samples of 37 and 56 Portuguese and Spanish nouns, which are frequently combined with both kinds of complement clauses, reveals clear differences between both noun classes and the usage context of the two types of complement clauses. Finite complements are preferred by mental and linguistic nouns, such as certeza 'certainty' and noticia 'news'. These nouns are also associated with the indicative mood in the subordinate clause. The nouns preferring the infinitive, on the other hand, are often modal (e.g. necesidad), and are associated with the subjunctive mood. Only nouns with mainly factual uses (e.g. facto and hecho 'fact') are frequently combined with both complement types. It is thus concluded that the finite and infinitive clausal complements are not functionally identical. In addition, historically there seems to be a shift towards more finite complements. That is, the infinitival complements are 
found to predominate in terms of usage frequency in the $16^{\text {th }}$ to $18^{\text {th }}$ centuries, whereas the finite clause complements become increasingly frequent in the $19^{\text {th }}$ and $20^{\text {th }}$ centuries.

Keywords: nominal complement clauses, infinitive, diachronic distinctive collexeme analysis, Spanish and Portuguese comparative syntax, corpus linguistics

\section{Resumen}

Este trabajo enfoca dos tipos de oraciones completivas de sustantivo, las completivas de verbo finito (el hecho de que vaya) y las de infinitivo (el hecho de ir), con el objetivo de determinar si entre ambos tipos hay "identidad funcional" (cf. Bogard \& Company 1989). Analizando dos muestras de 37 y 56 sustantivos que se combinan frecuentemente con ambos tipos de completivas en portugués y español, respectivamente, se observa que hay claras diferencias entre las clases de sustantivos y los contextos de uso de ambos tipos de completivas. Las completivas finitas se usan con sustantivos mentales y lingüísticos (como certeza y noticia), que se asocian, además, con el modo indicativo, mientras que los sustantivos modales (como necesidad) prefieren las completivas de infinitivo, y estos sustantivos se asocian con el modo subjuntivo. En cambio, los sustantivos de uso factual (e.g. facto/fato y hecho) presentan preferencias variables por uno u otro tipo de completiva. Así, se concluye que las completivas finitas no funcionan de modo idéntico a las completivas de infinitivo. Además, se observa un desplazamiento diacrónico a favor de las completivas finitas, de modo que las completivas de infinitivo son más frecuentes en los primeros siglos analizados (XVI, XVII y XVIII), mientras que se detecta una frecuencia creciente de las completivas finitas en los siglos XIX y xx.

Palabras clave: oraciones completivas de sustantivo, infinitivo, análisis distintivo de colexemas diacrónico, sintaxis comparada del español y del portugués, lingüística de corpus 


\section{INTRODUCCIÓN ${ }^{1}$}

En español y portugués existen dos variantes sintácticas principales de las oraciones completivas de sustantivo, a saber, una con el verbo subordinado en infinitivo ( $\mathrm{N} d e+$ infinitivo) y otra con una oración finita (N (de) que). Estas dos subconstrucciones se ejemplifican en (1a) y (1b).

(1) a. La idea de ir a tu casa no me gusta. / Não gosto da ideia de ir para a tua casa.

b. La idea de que vayas a mi casa tampoco me gusta. / Não gosto da ideia de que vás para a minha casa.

Con respecto a la variante en (1b) es bien sabido que la introducción de la preposición de delante de la conjunción que es una evolución relativamente tardía, tanto en español donde tiene lugar en el siglo XVI (Bogard \& Company 1989; Serradilla 1995; 2010; Girón Alconchel 2004; Pountain 2014), como en portugués, donde su uso parece extenderse en el XVII (Granvik 2015). Con respecto al español, Bogard \& Company (1989: 260) sugieren que la introducción de la preposición de delante de la conjunción subordinante que puede explicarse por

${ }^{1}$ Este trabajo se inserta en el Proyecto de investigación FFI2015-64080-P, Procesos de gramaticalización en la historia del español (V): gramaticalización, lexicalización y análisis del discurso desde una perspectiva histórica, del Ministerio de Economía y Competitividad. Quiero agradecer los valiosos comentarios de los dos revisores anónimos de una versión anterior de este trabajo. Desde luego, todas las posibles inconsistencias y errores que puedan encontrarse son de mi entera responsabilidad. 
el hecho de que hay "identidad funcional" entre uno y otro tipo de complemento (infinitivo y finito).

A este respecto, Granvik (2015: 391-92) constata que la coincidencia entre el español y el portugués en los sustantivos que más típicamente funcionan como núcleo de oraciones completivas -por ejemplo, idealideia, convicción/conviç̧ão, conclusión/conclusão, impresión/impressão de que - es mayor que la coincidencia entre los dos tipos de completivas -necesidad/necessidade, posibilidad/possibilidade, obligación/obrigação $d e+$ infinitivo. Es decir, no son los mismos sustantivos los que se combinan con de que y con el infinitivo. Por otro lado, en su estudio sobre la diacronía de la construcción $\mathrm{N}$ be that del inglés, Schmid \& Mantlik (2015: $\$ 5.3)$ mencionan que en esta lengua hubo una diferenciación semántica entre verbos y sustantivos que prefieren complementos infinitivos y otros que se combinan con completivas finitas. Fernández Lagunilla (1992: 394), por su parte, en su estudio de los complementos oracionales de verbos de percepción, constata que

en la lengua medieval la construcción de infinitivo aparece en contextos o distribuciones sintácticas de las que ha desaparecido en la lengua actual a favor de otras construcciones tales como la de gerundio, de adjetivo-participio y la completiva con que.

Todo esto parece indicar que la idea de "identidad funcional" de los complementos infinitivos y finitos quizá no sea un hecho consumado. Ahora, es evidente que el concepto de "identidad funcional" puede interpretarse de modo más o menos estricto, según se quiera enfatizar el 
primer o el segundo término. Por un lado, el concepto puede asociarse con la idea de función gramatical. Bajo esta concepción, todos los elementos que pueden ejercer la misma función sintáctica se consideran miembros de la misma clase funcional. Así, puede hablarse de subordinadas sustantivas y adjetivas según ejerzan la función típica de un sustantivo o un adjetivo. Así, en veo al chico y veo que hay un chico allí la oración subordinada introducida por que ejerce la función de un sustantivo: veo X, mientras que en el chico alto y el chico que está allí la subordinada funciona como adjetivo en relación con el sustantivo. Desde esta perspectiva, es evidente que infinitivos y oraciones completivas ejercen la misma función de modificadores de un sustantivo que otro sustantivo: Tengo necesidad de ayuda - ser ayudado - que me ayuden.

Por otro lado, haciendo énfasis en el término identidad, se esperaría que dos o más elementos funcionalmente idénticos fueran altamente compatibles en cuanto a su funcionamiento en la lengua, es decir, su uso. Según esta lógica, donde puede usarse un tipo de completiva debería poder usarse también el otro. Así, si hay identidad funcional en sentido estricto, es de suponer que el complemento infinitivo y el finito se combinarán indistintamente con los mismos sustantivos.

El objetivo de este trabajo es analizar la evolución diacrónica de la complementación oracional de sustantivos en español y portugués, con énfasis en el contraste entre las variantes con infinitivo y con oración completiva finita. Más específicamente, mediante el análisis de datos extraídos del Corpus del español (Davies 2002-) y del Corpus do Português (Davies \& Ferreira 2006-), me propongo determinar hasta qué punto la idea de "identidad funcional", en su interpretación más estricta, entre 
una y otra variante encuentra apoyo en los datos. También me interesa comprobar si en la historia de estas dos lenguas pueden identificarse tendencias de especialización de la construcción, de modo que algunos sustantivos se van asociando a los complementos infinitivos mientras que otros se asocian a complementos finitos.

El trabajo está estructurado de la siguiente manera. En $\$ 2$ se presentan las bases teóricas del trabajo: se introducen brevemente las oraciones completivas de sustantivo, y se caracterizan las oraciones subordinadas de verbo finito y de infinitivo. Sobre la base de las consideraciones teóricas se presentan dos hipótesis de trabajo más específicas. El apartado $\$ 3$ está dedicado al corpus y los métodos de análisis utilizados. En el apartado $\$ 4$ se presentan los resultados del análisis de las dos lenguas, haciendo hincapié en las diferencias y semejanzas entre ellas y entre los dos tipos de complementos desde la perspectiva de los sustantivos núcleo. También se discuten las implicaciones de estos resultados para la complementación oracional de sustantivos en las dos lenguas. Las conclusiones se presentan en el apartado $\$ 5$.

\section{BASES TEÓRICAS}

Aunque el estudio de las oraciones completivas en español tiene una larga historia, los trabajos sobre las completivas que tienen como núcleo un elemento nominal son relativamente escasos. Una característica de estos estudios (cf. Tarr 1922; Bogard \& Company 1989; Leonetti 1993; 1999; Delbecque 1998; 2000; Rodríguez Espiñeira 2003; 2010) es que la gran 
mayoría de ellos basan su análisis en la complementación verbal. Por consiguiente, los complementos oracionales de los sustantivos se relacionan con los complementos verbales, y los sustantivos que funcionan como núcleo de oraciones completivas se caracterizan frecuentemente como deverbales (cf. Fernández Ramírez 1986 [1953]: \$78: 4-5). Por ejemplo, la completiva de esperanza en la esperanza de que gane el Cádiz puede equipararse al complemento oracional del verbo esperar en una oración como esperamos que gane el Cádiz. Este hecho parece motivar que Leonetti (1993), Escandell Vidal (1995) y Moreno de Alba (2009) basen su tratamiento de las oraciones completivas de sustantivo en la distinción entre completivas argumentales, donde hay paralelo con los complementos del verbo, y las apositivas, donde no hay tal paralelo. ${ }^{2}$

Ahora, si se tiene en cuenta que, según Bogard \& Company (1989: 260-261) solo los sustantivos del tipo timor, pavor, periculum, relacionados, por su parte, con verbos de temor, se construían con oraciones completivas en latín (introducidas por el nexo ne), tomar el paralelo existente entre verbos y sustantivos como punto de partida parece razonable. Sin embargo, a día de hoy, con cientos de sustantivos que se combinan con oraciones completivas, otorgarles tal protagonismo a los sustantivos deverbales quizá no sea lo más adecuado. De hecho, como han demostrado los estudios de Lüdtke (1998), Delbecque (1998; 2000), Schmid (2000) y Rodríguez Espiñeira (2003; 2010; 2015), la función de los

${ }^{2}$ La distinción entre completivas argumentales y apositivas parece haber sido introducida por Leonetti (1993): en el primer caso "la subordinada está seleccionada por el nombre y completa su significación; en el segundo, "simplemente identifica el referente del sintagma nominal que la precede" (1993: 8). 
sustantivos que ejercen de núcleo de oraciones completivas va mucho más allá de reflejar simplemente una estructura argumental propia de los verbos. Más bien, estos sustantivos funcionan como clasificadores, interpretadores o encapsuladores del contenido proposicional que expresa la oración completiva.

Esta función clasificadora es relativamente evidente en un caso de completiva apositiva con un sustantivo como idea en (1a) y (1b), donde las cláusulas ir a tu casa y que vayas a mi casa son clasificadas como una idea. Sin embargo, la función clasificadora o encapsuladora es patente también en muchos casos de completivas argumentales, como revelan los ejemplos en (2). En estos ejemplos, está claro que demostrar su afecto es clasificado como una necesidad, y que detener al agresor supone una orden, aunque las oraciones también corresponden a complementos directos de los verbos necesitar y ordenar.

(2) a. Y sentía la necesidad de demostrar su afecto.

b. El juez dio la orden de detener al agresor.

(3) el anuncio de que "Viagra" llegará a las farmacias el próximo otoño. (CE, DR:Listin:98May23, xx)

Ahora bien, como se constata en la NGLE (\$26.11q), “[1] os límites entre las subordinadas sustantivas de naturaleza argumental y las que se interpretan en estructuras atributivas son [...] imprecisos". Además, como revela el estudio de Delbecque (1998), los hablantes no parecen conscientes de la distinción entre completivas argumentales y apositivas. De hecho, en un 
ejemplo como (3) no está del todo claro que se pueda determinar si se trata de una completiva apositiva o argumentativa. Para autores como Lüdtke (1998), Schmid (2000), Delbecque (1998; 2000) y Rodríguez Espińeira (2003; 2010), entonces, indistintamente de si un sustantivo abstracto se relaciona con un verbo y tiene estructura argumental (esperanza, sensación, conclusión, intuición), o no (idea y hecho), su interpretación en el discurso típicamente solo puede actualizarse por medio de su "complemento".

Si los estudios sobre las completivas de sustantivo son poco frecuentes, son más raros todavía los trabajos que contrasten los diferentes tipos de completivas en este contexto. Es decir, que intenten esclarecer si hay alguna diferencia entre decir, por ejemplo, el hecho de que haya ganado (el Cádiz) y el hecho de ganar (el Cádiz). Una mención explícita de este contraste es la de Gärtner (1998) quien, con respecto a la construcción factiva del portugués ( o facto de + oración), constata que es más frecuente la construcción con el infinitivo flexionado que con una oración finita. Sin embargo, Gärtner no ofrece ninguna explicación del porqué de esta preferencia, por lo que no hay que descartar que el contexto de los complementos verbales pueda ser un importante punto de partida para contrastar las completivas finitas y las infinitivas.

Antes de pasar al análisis de las posibles diferencias de uso entre estos dos tipos de completivas, cabe detenerse en dos caracterizaciones teóricas y conceptuales como las de Langacker (2008a) y Silva (2008). En términos de Langacker (2008a: 437):

Though often interchangeable, finite and nonfinite complements are not at all equivalent. They differ not just formally but in their meaning and 
discourse function. By definition, finite clauses invoke a conceptualizer and indicate its stance vis-à-vis some occurrence. They are thus more closely associated with epistemic judgments and conceptions of reality.

En cambio, la oración infinitiva "lacks both grounding and an overt subject. In and of itself, therefore, it does not specify any particular event whose reality can be assessed" (2008a: 433). Así, aunque Langacker admite una cierta afinidad entre el infinitivo y la oración finita, niega que puedan considerarse equivalentes.

Silva (2008), por su parte, establece un esquema detallado que destaca las características (distintivas) de los tres tipos de oraciones subordinadas del portugués: la oración finita, la oración con infinitivo flexionado y la que lleva infinitivo no-flexionado. Con los términos traducidos al español, la Tabla 1 reproduce el esquema de Silva (2008: 233).

Como queda claro al observar las caracterizaciones de Langacker (2008a) y Silva (2008), las oraciones subordinadas infinitivas se distinguen por su menor grado de independencia en prácticamente todos los aspectos, es decir, pueden considerarse claramente subordinadas en relación con la oración principal. Las oraciones finitas, en cambio, se encuentran casi al mismo nivel que la oración principal en términos de complejidad, independencia y prominencia conceptual (cf. Vesterinen 2006: 165-167). ${ }^{3}$ Sobre esta base, entonces, cabe esperar que el uso de los diferentes tipos de complementos no sea idéntico para todos los sustantivos.

3 Este parece ser uno de los motivos por los que el mismo concepto de subordinación oracional, especialmente en lo que se refiere a oraciones finitas, se haya cuestionado últimamente (cf. la discusión en Langacker 2008b). 


\section{Tabla 1. Continuum (o "cline") conceptual de las oraciones subordinadas (adverbiales) con verbo finito, infinitivo flexionado e infinitivo no-flexionado en portugués. Tomado de Silva (2008: 233)}

\begin{tabular}{|c|c|c|}
\hline MÁs & & $\longrightarrow$ MENOS \\
\hline \multicolumn{3}{|c|}{ INDEPENDENCIA } \\
\hline $\begin{array}{l}\text { V independiente: } \\
\text { morfología plena } \\
\text { sin elevación (raising) } \\
\text { sujeto específico y } \\
\text { nominativo } \\
\text { dos cláusulas }\end{array}$ & $\begin{array}{l}\text { V independiente: alguna } \\
\text { morfología } \\
\text { sin elevación (raising) } \\
\text { sujeto específico y nominativo } \\
\text { dos cláusulas }\end{array}$ & $\begin{array}{l}\text { V independiente: sin } \\
\text { morfología } \\
\text { elevación (raising), cl. } \\
\text { climbing/ infinitivo desnudo } \\
\text { sujeto no específico/raised } \\
\text { una sola cláusula }\end{array}$ \\
\hline \multicolumn{3}{|c|}{ ESPECIFICIDAD PROCESUAL } \\
\hline $\begin{array}{l}\text { ejemplo de tipo de proceso } \\
\text { escaneo secuencial } \\
\text { temporal } \\
\text { expresión más verbal }\end{array}$ & $\begin{array}{l}\text { tipo de proceso (personal) } \\
\text { escaneo sumario } \\
\text { holístico y atemporal }\end{array}$ & $\begin{array}{l}\text { tipo de proceso } \\
\text { escaneo sumario } \\
\text { holístico y atemporal } \\
\text { expresión más nominal }\end{array}$ \\
\hline \multicolumn{3}{|c|}{ ANCLAJE (GROUNDING) } \\
\hline anclaje pleno & anclaje mínimo (de persona) & sin anclaje \\
\hline \multicolumn{3}{|c|}{ PROMINENCIA } \\
\hline prominencia plena & prominencia del trayector & $\begin{array}{l}\text { ninguna prominencia } \\
\text { eventiva }\end{array}$ \\
\hline \multicolumn{3}{|c|}{ OBJETIVIDAD/SUBJETIVIDAD } \\
\hline $\begin{array}{l}\text { + objetividad: evento } \\
\text { + subjetividad: (eje } \\
\text { subjetivo) }\end{array}$ & + objetividad: trayector & $\begin{array}{l}\text { - objetividad: proceso } \\
\text { - subjetividad: (eje } \\
\text { subjetivo) }\end{array}$ \\
\hline oración subordinada FINITA & $\begin{array}{l}\text { oración subordinada de } \\
\text { INFINITIVO FLEXIONADO }\end{array}$ & $\begin{array}{l}\text { oración subordinada de } \\
\text { INFINITIVO NO-FLEXIONADO }\end{array}$ \\
\hline
\end{tabular}


Haciendo caso omiso del infinitivo flexionado, la falta de independencia de la oración infinitiva con respecto a la oración principal se hace patente en dos aspectos muy concretos: por un lado, en la ausencia de marcas de persona, y por otro, en la ausencia de marcas de tiempo y modo. La cuestión de la correferencialidad del sujeto entre la oración principal y subordinada tradicionalmente se ha considerado de gran importancia para la elección del tipo de subordinada (cf. Moreno de Alba 2009: 1387; ngLe $\$ 26.11$ i; Raposo et al. 2013: \$36.1.2.1). En espańol, para introducir un sujeto no recuperable contextualmente (es decir, no correferencial) es necesario recurrir a una completiva finita. En cambio, en portugués "nas orações infinitivas sem flexão de concordância, o sujeito não pode geralmente ser expresso" (Raposo et al. 2013: 1827-1828).

Sin embargo, como se ha destacado en muchas ocasiones, la realidad es bastante más compleja que esto. Así, por un lado, es frecuente el uso de formas flexionadas (infinitivo o verbo finito) aunque los sujetos sean correferenciales (Vesterinen 2006; Vanderschueren \& Diependaele 2013; Vanderschueren \& de Cuypere 2014). Por otro lado, también es frecuente el uso del infinitivo, aunque los sujetos no sean correferenciales (cf. De Mello 1998), como revela el ejemplo de el hecho de ganar el Cádiz, donde el Cádiz es interpretado como sujeto del infinitivo.

Hernanz (1999), por su parte, destaca la importancia de la ausencia de marcas de tiempo y modo en las oraciones de infinitivo. Según esta autora, los complementos de infinitivo pueden alternar con complementos finitos con el verbo en subjuntivo, pero son incompatibles con los complementos finitos en indicativo. Es decir, los predicados (de voluntad 
e influencia) que rigen subjuntivo pueden combinarse fácilmente con complementos infinitivos, mientras que los predicados (de percepción y comunicación) que se combinan con completivas en indicativo generalmente no aceptan el infinitivo. Así, la propuesta de Hernanz (1999) es que hay compatibilidad entre los complementos finitos en subjuntivo y los complementos de infinitivo puesto que el subjuntivo no es un modo verbal pleno en la misma medida que el indicativo:

la manifestación sintáctica habitual tanto del subjuntivo como del infinitivo (salvo en los casos de modalidad marcada) es la subordinación: ni uno ni otro expresan proposiciones a las que se les pueda asignar un valor de verdad. Ello puede considerarse una consecuencia lógica del carácter parcialmente defectivo desde el punto de vista temporal que comparten ambos frente al indicativo. (1999: 2286-2287)

Tomando el continuum conceptual de Silva (2008) como punto de partida, lo que parece sugerir el análisis de Hernanz (1999) es que quizá habría que introducir una categoría más en el lado finito del continuum, separando las subordinadas finitas en indicativo de las que tienen el verbo en subjuntivo.

Entre los predicados que toman completivas finitas (en subjuntivo) y de infinitivo se encuentran los verbos de influencia. Así, según la NGLE $(\$ 26.11 \mathrm{e})$

son sinónimas o casi sinónimas Te permito que vayas y Te permito ir, Yo no te obligo a que comas esas porquerias y Yo no te obligo a comer esas porquerias; 
Nos dieron la orden de que saliéramos y Nos dieron la orden de salir, y otras muchas en las que el complemento directo o indirecto del verbo principal constituye el antecedente del sujeto tácito del infinitivo.

En el otro extremo están los verbos de percepción y comunicación, que se construyen típicamente con indicativo:

los complementos de infinitivo de los verbos de percepción suelen expresar acciones o sucesos (Veíamos enojarse a la gente), mientras que las subordinadas sustantivas de verbo finito que se corresponden con esos infinitivos expresan juicios de valor, así como situaciones y estados de cosas de las que alguien se apercibe (Veíamos que la gente se enojaba). No se obtiene, pues, en estos casos, identidad de sentidos. (NGLE $\$ 26.11 \mathrm{~g}$ )

Una división semejante se encuentra también en la clasificación que hace Givón (2001) de los verbos que se construyen con complementos oracionales. Givón (2001: 1, \$3.3.7) distingue entre cuatro tipos de verbos: 1) verbos modales (de volición o incepción); 2) verbos de manipulación (causar, prevenir, prohibir); 3) verbos de percepción, cognición y de habla (ver, saber, decir); y 4) verbos que toman sujetos oracionales. La relevancia de esta clasificación verbal para el presente estudio es que Givón relaciona los tres tipos de verbos con un continuum de integración de eventos o de unión de cláusulas. Así,

the grammar of complementation furnishes one of the best, and cross-linguistically most reliable, examples of iconicity in syntax. [...] The stronger 
the semantic bond between the two events, the more extensive will be the syntactic integration of the two clauses into a single though complex clause. [...] "The cognitive-semantic dimensions of complementation [...] correlate closely with the semantic properties of the main verb. (2001: 2, 39-40)

En el continuum de Givón los verbos de percepción, cognición y habla ( $\mathrm{PCH}$ ) forman lazos interoracionales débiles, mientras que los verbos modales y de manipulación forman lazos fuertes entre oraciones. De ahí que los verbos modales frecuentemente se consideren semi-auxiliares, y se combinen con complementos infinitivos, formando estructuras perifrásticas, mientras que los verbos de $\mathrm{PCH}$ prefieren complementos oracionales con verbo finito, en los que la proposición "subordinada" mantiene un alto grado de independencia conceptual. Según esta lógica, los verbos de manipulación, o de volición e influencia, que en español y portugués son los que son máximamente compatibles con el subjuntivo, se sitúan en un punto intermedio. ${ }^{4}$

Aunque estas caracterizaciones teóricas del contraste entre las oraciones subordinadas de infinitivo y de verbo finito se basan principalmente en usos adverbiales (que típicamente modifican a predicados verbales), suponen un interesante punto de partida para el estudio de las oraciones completivas de sustantivo. Así, la cuestión de la correferencialidad

${ }^{4}$ Hay que tener en cuenta, sin embargo, que la selección de modo como criterio diferenciador entre los diferentes tipos de verbos solo supone una solución parcial: la distinción se aplica en contextos oracionales afirmativos, pero en contextos oracionales negados la selección modal se ve significativamente afectada, hasta tal punto que puede cuestionarse si depende realmente del predicado. 
o recuperabilidad del sujeto, por un lado, y la compatibilidad semántica entre el modo subjuntivo y el infinitivo, por otro, permiten formular dos hipótesis de trabajo:

1. El uso del infinitivo será más frecuente con sujetos correferenciales y el uso de completivas finitas será más frecuente cuando en la subordinada se introduce un nuevo sujeto (cf. Moreno de Alba 2009: \$12.3.7).

2. El uso del infinitivo será más frecuente con sustantivos modales y de influencia (semánticamente compatibles con el modo subjuntivo), mientras que el uso de completivas finitas será más frecuente con sustantivos de percepción, cognición y habla.

Aunque la primera hipótesis pueda parecer relativamente obvia, el hecho de tratarse de núcleos nominales hace que la situación sea muy distinta en comparación con oraciones principales con predicados verbales. La segunda hipótesis, por su parte, hace referencia a dos aspectos: las clases semánticas de los sustantivos y su asociación con el modo de la subordinada.

Para la clasificación semántica existen dos clasificaciones anteriores que tienen relevancia para este trabajo. Están, por un lado, los tres tipos de predicados verbales que rigen complementos oracionales de Givón (2001): 1) los modales, 2) los de manipulación y 3) los de percepción, cognición y habla ( $\mathrm{PCH})$. Por otro lado, está la clasificación que hace Schmid (2000) de los sustantivos encapsuladores en seis tipos de usos: 1) factuales, 2) lingüísticos, 3) mentales, 4) modales, 5) eventivos, y 
6) circunstanciales. Las clases 2,3 y 4 de Schmid se reubican fácilmente entre los tres tipos de Givón, pero las clases 1, 5 y 6 , son más problemáticas ya que incluyen sustantivos que pueden considerarse tanto de manipulación como de PCH.

Basada como está en los usos de los sustantivos encapsuladores, la clasificación de Schmid (2000) supone el punto de partida más importante para este estudio, pero donde sea pertinente para el análisis recurriré a los tres tipos de Givón (2001) como apoyo. Esto será preciso particularmente con los sustantivos factuales, entre los que algunos como condición, riesgo, efecto, peligro y fin se construyen típicamente con subjuntivo, mientras que otros como verdad y sentido se construyen típicamente con indicativo. Cabe destacar que la clasificación de Schmid (2000) se basa en usos de los sustantivos, lo cual implica que un sustantivo puede incluirse en varias clases diferentes si su significado exacto se ve modificado por el contexto de uso. En este trabajo, que se basa en la manipulación cuantitativa de un gran número de datos, no ha sido posible diferenciar y desambiguar los diferentes matices contextuales de los sustantivos, sino que los sustantivos se han incluido en las clases que se manejan en los apartados de análisis según su significado típico.

En el apartado de análisis (\$4), los diferentes sustantivos se analizarán desde tres perspectivas. En un nivel general, se prestará atención a las clases semánticas de los sustantivos; en el nivel del uso contextual se enfocará, por un lado, la correferencialidad de sujetos, y, por otro, el modo de la subordinada en la variante con verbo finito ( $\mathrm{N}$ de que). 


\section{Corpus y MÉTOdo}

Para realizar el estudio he recurrido a dos grandes corpus diacrónicos, el Corpus del español (Davies 2002-) y el Corpus do Português (Davies \& Ferreira 2006-), respectivamente, que están libremente disponibles en la red. Aparte de que contienen una gran cantidad de datos, una ventaja de estos dos corpus es que son obra del mismo investigador y comparten la misma configuración e interfaz de búsquedas, por lo que constituyen una buena base para el estudio contrastivo de estas dos lenguas. Además, incluyen la anotación de un considerable número de propiedades gramaticales, lo que permite extraer concordancias utilizando búsquedas del tipo "[ $\left.\mathrm{NN}^{*}\right]$ de que" o "[ $\left.\mathrm{NN}^{*}\right]$ de $\left[\mathrm{VR}^{*}\right]$ ", etc. que corresponden a "cualquier sustantivo seguido de de que" y "cualquier sustantivo seguido por cualquier infinitivo no flexionado". Siendo corpus diacrónicos, también permiten extraer ejemplos correspondientes a diferentes épocas, más exactamente, a los siglos XIII a XX en el caso del Corpus del español (CE en adelante) y a los siglos XIV a XX en el caso del Corpus do Português (CP en adelante).

Al trabajar con grandes corpus electrónicos, el primer paso para acceder a los datos es extraerlos de los corpus. El segundo paso, que es tan importante como el primero, es limitar el número de casos que se analizarán. En este trabajo, dado que el objetivo es contrastar dos tipos de oraciones completivas, el análisis se limitará a aquellos sustantivos que más frecuentemente se combinan con ambos tipos. La muestra inicial incluye 362 formas sustantivas en español y 483 en portugués. Estas cifras corresponden a las formas que tienen una frecuencia de uso por encima del $0.1 \%$ de todos los casos de la secuencia $\mathrm{N}$ de que y $\mathrm{N}$ de + infinitivo, 
respectivamente. Puesto que el Corpus del español (CE) incluye un total de 46512 casos de la secuencia $\mathrm{N}$ de que, están incluidos en la muestra inicial las formas sustantivas que ocurren al menos 46 veces ante de que. Estas son 162 en total. La cifra correspondiente de la secuencia $\mathrm{N} d e+$ infinitivo es de 110105 casos, por lo que se incluyen las formas sustantivas con una frecuencia mayor a 110 casos. Estas son 200 en total.

En portugués se ha procedido esencialmente del mismo modo, con la diferencia de que se han incluido también los casos en los que el complemento tiene la forma de infinitivo flexionado (que tiene su propia codificación en el CP). El CP incluye 20619 casos de la secuencia $\mathrm{N}$ de que, por lo que la muestra inicial incluye las 129 formas sustantivas que ocurren 20 veces o más en esta construcción. Con el infinitivo no flexionado son 52414 los casos que se encuentran en el cP, y son 186 las formas sustantivas que se usan 52 veces o más seguidos de la secuencia de + infinitivo. Finalmente, hay 1284 casos de la secuencia $\mathrm{N}$ de infinitivo flexionado, por lo que he incluido también las 168 formas sustantivas que ocurren al menos dos veces en esta combinación.

Para poder comparar los sustantivos que prefieren uno u otro tipo de completivas, hay que combinar las muestras iniciales para determinar qué sustantivos se combinan efectivamente con ambos tipos de complementos, y qué sustantivos prefieren uno u otro tipo de complemento. En español, de las 362 formas sustantivas inicialmente identificadas, 190 solo se incluyen en una de las muestras iniciales: 114 se combinan únicamente con el infinitivo, y 76 solo con de que. En cambio, son 86 las formas sustantivas que se construyen con ambos tipos de complementos con una frecuencia lo suficientemente elevada como para incluirse en 
ambas muestras iniciales. Así, la muestra combinada del español incluye 86 sustantivos que se combinan 46 veces o más con de que y 110 veces o más con de + infinitivo (cf. la Tabla 2).

En portugués se han combinado primero las formas sustantivas que se combinan con los dos tipos de infinitivos. Esta muestra combinada de infinitivos del portugués incluye 273 formas sustantivas diferentes. Combinando estas 273 formas sustantivas con las 129 que se combinan con de que al menos 20 veces, se observa que son 276 las formas sustantivas que solo se incluyen en una de las muestras: de estas, 210 corresponden al infinitivo (flexionado y no flexionado) y 66 a de que. Ello deja 63 que se combinan lo suficientemente a menudo con ambos tipos de complementos para incluirse en la muestra combinada (20 o más veces con de que, 52 o más veces con el infinitivo no flexionado y dos veces o más con el infinitivo flexionado). Estas cifras se resumen en la Tabla 2.

Sin embargo, no todos los sustantivos que ocurren ante de que y de+ infinitivo funcionan realmente como núcleo de una oración completiva. Ejemplos de sustantivos que no se clasifican como tales son nombres concretos, como casa, hombre, señor, y abstractos, del tipo tiempo, modo, forma, governo, etc. Por este motivo las muestras finales de sustantivos cuyo uso en ambas construcciones se contrastará se limita aún más. Así, de los 63 sustantivos portugueses, solo 39 pueden considerarse realmente núcleos de una oración completiva. ${ }^{5}$ De igual modo, de los 86 sustantivos españoles solo 56 se incluyen en la muestra final.

5 En la extracción de ejemplos del corpus he respetado la variación ortográfica en la fase inicial. En fases posteriores he juntado los casos de las variantes minoritarias de modo que cada sustantivo esté representado solo una vez. Sin embargo, hay una excepción: el sustantivo 
Tabla 2. Número de sustantivos que más frecuentemente se combinan con los diferentes tipos de completivas

\begin{tabular}{llll}
\hline Muestra inicial & ES & PT todo & PT infinitivos \\
\hline $\mathrm{N}$ de que & $162(\mathrm{n}>46)$ & $129(\mathrm{n}>20)$ & - \\
$\mathrm{N}$ de infinitivo & $200(\mathrm{n}>110)$ & 273 & $186(\mathrm{n}>52)$ \\
$\mathrm{N}$ de infinitivo INFL & - & - & $\begin{array}{l}168(\mathrm{n}>2) \\
354>273 \text { formas } \\
\text { Suma }\end{array}$ \\
\hline Muestra combinada & 362 & 402 & \\
\hline Solo N de que & & & \\
Solo N de infinitivo & 114 & 66 & \\
N de que y N de infinitivo & $86+86$ & 210 & \\
Suma & 362 & $63+63$ & \\
\hline
\end{tabular}

Cabe destacar que el hecho de basar el corpus en las secuencias $\mathrm{N}$ de que y $\mathrm{N} d e+$ infinitivo, hace que el alcance diacrónico de las muestras no sea completa. El motivo principal es que, según se constató en la introducción, la secuencia $\mathrm{N}$ de que no supone un indicio de oraciones completivas hasta el siglo XVI en espańol y el Xviı en portugués. Esta es una

facto del portugués presenta dos variantes ortográficas en la lengua actual. En la norma brasileña facto se escribe sin la $c$, es decir, como fato. En el portugués europeo, en cambio, se usa la forma facto, evitando la homonimia con el sustantivo fato 'traje'. Como podrá observarse más adelante, estas variantes ortográficas son importantes, pues revelan una interesante diferencia entre las dos variantes del portugués. Si bien hablo de 39 sustantivos arriba, estos son en realidad solo 37 , ya que tanto facto como fato tienen una entrada propia al lado de facto* que recoge la suma de ambas variantes ortográficas. 
importante limitación del análisis, pues la ausencia de las completivas del tipo $\mathrm{N}$ que implica que solo se podrá dar cuenta de una parte del contraste entre completivas finitas e infinitivas. Sin embargo, de momento, al menos, la desambiguación entre oraciones completivas y relativas de la secuencia $\mathrm{N}$ que solo puede hacerse manualmente caso por caso, por lo que el manejo de grandes cantidades de datos como es el caso de este análisis no resulta factible.

Ahora, para determinar la preferencia de cada sustantivo por una $u$ otra construcción (es decir, el complemento finito o infinitivo) de un modo más exacto, recurrí al análisis distintivo de colexemas (distinctive collexeme analysis) elaborado por Gries \& Stefanowitsch (2004). Este análisis permite determinar cuáles son los sustantivos que más estrechamente se asocian con los dos tipos de completivas más allá de la mera frecuencia de uso. Según puede observarse en las Tablas 3 y 5, los resultados indican que existen tres grupos de sustantivos en ambas lenguas: los que prefieren el infinitivo, los que se decantan por la completiva finita $y$, finalmente, los que se combinan con los dos tipos de completivas. Empezando por la Tabla 3, se observa que en español hay 10 sustantivos que prefieren combinarse con completivas finitas (son los primeros de la tabla y van marcados con un fondo color naranja). Al final de la tabla se encuentran 17 sustantivos que muestran una clara preferencia por complementos infinitivos (marcados con color morado), mientras que los 29 restantes se combinan indistintamente con los dos tipos de complementos. 
Tabla 3. Los 56 sustantivos del español sometidos al análisis distintivo de colexemas (ADC)

\begin{tabular}{|c|c|c|c|c|c|c|}
\hline & 46512 & & 110105 & & & \\
\hline LEX & $\mathrm{N}$ de que & $\neg \mathrm{N}$ de que & $\mathrm{N} d e$ infinitivo & $\neg \mathrm{N} d e$ infinitivo & TEFY $\mathrm{p}$ & OR \\
\hline noticia & 484 & 46028 & 158 & 109947 & $2.20 \mathrm{E}-16$ & 7.316939 \\
\hline seguridad & 335 & 46177 & 138 & 109967 & $2.20 \mathrm{E}-16$ & 5.780432 \\
\hline$d u d a$ & 381 & 46131 & 190 & 109915 & $2.20 \mathrm{E}-16$ & 4.777853 \\
\hline sentido & 374 & 46138 & 231 & 109874 & $2.20 \mathrm{E}-16$ & 3.855983 \\
\hline fe & 205 & 46307 & 127 & 109978 & $2.20 \mathrm{E}-16$ & 3.833154 \\
\hline hecho & 1057 & 45455 & 677 & 109428 & $2.20 \mathrm{E}-16$ & 3.759019 \\
\hline condición & 193 & 46319 & 138 & 109967 & $2.20 \mathrm{E}-16$ & 3.320168 \\
\hline señal & 364 & 46148 & 283 & 109822 & $2.20 \mathrm{E}-16$ & 3.060891 \\
\hline ocasión & 181 & 46331 & 170 & 109935 & $2.20 \mathrm{E}-16$ & 2.526346 \\
\hline caso & 996 & 45516 & 1150 & 108955 & $2.20 \mathrm{E}-16$ & 2.073264 \\
\hline idea & 788 & 45724 & 925 & 109180 & $2.20 \mathrm{E}-16$ & 2.034208 \\
\hline temor & 443 & 46069 & 571 & 109534 & $2.20 \mathrm{E}-16$ & 1.844518 \\
\hline causa & 729 & 45783 & 1075 & 109030 & $2.20 \mathrm{E}-16$ & 1.614951 \\
\hline verdad & 76 & 46436 & 121 & 109984 & 0.007845 & 1.487653 \\
\hline esperanza & 539 & 45973 & 1070 & 109035 & 0.0009022 & 1.194697 \\
\hline promesa & 63 & 46449 & 132 & 109973 & 0.4332 & 1.129983 \\
\hline cargo & 173 & 46339 & 363 & 109742 & 0.201 & 1.128656 \\
\hline señales & 78 & 46434 & 164 & 109941 & 0.3984 & 1.126083 \\
\hline pretexto & 159 & 46353 & 336 & 109769 & 0.2373 & 1.120614 \\
\hline circunstancia & 130 & 46382 & 275 & 109830 & 0.3009 & 1.119383 \\
\hline miedo & 219 & 46293 & 470 & 109635 & 0.242 & 1.103513 \\
\hline fin & 1457 & 45055 & 3305 & 106800 & 0.171 & 1.045002 \\
\hline posibilidad & 443 & 46069 & 1108 & 108997 & 0.3424 & 0.9459541 \\
\hline esperanzas & 116 & 46396 & 292 & 109813 & 0.6254 & 0.9402617 \\
\hline ventaja & 77 & 46435 & 200 & 109905 & 0.5111 & 0.9112419 \\
\hline cuestión & 60 & 46452 & 163 & 109942 & 0.3797 & 0.8712148 \\
\hline consuelo & 64 & 46448 & 174 & 109931 & 0.357 & 0.8705351 \\
\hline
\end{tabular}




\begin{tabular}{|c|c|c|c|c|c|c|}
\hline & 46512 & & 110105 & & & \\
\hline LEX & $\mathrm{N}$ de que & $\neg \mathrm{N}$ de que & $\mathrm{N} d e$ infinitivo & $\neg \mathrm{N}$ de infinitivo & TEFY $\mathrm{p}$ & OR \\
\hline riesgo & 223 & 46289 & 625 & 109480 & 0.03165 & 0.8438901 \\
\hline razón & 321 & 46191 & 902 & 109203 & 0.008289 & 0.8413564 \\
\hline palabra & 99 & 46413 & 280 & 109825 & 0.129 & 0.8366489 \\
\hline términos & 49 & 46463 & 140 & 109965 & 0.266 & 0.8283623 \\
\hline conveniencia & 52 & 46460 & 150 & 109955 & 0.2477 & 0.8204528 \\
\hline orden & 208 & 46304 & 607 & 109498 & 0.008924 & 0.8103435 \\
\hline peligro & 204 & 46308 & 614 & 109491 & 0.002746 & 0.7856538 \\
\hline efecto & 79 & 46433 & 269 & 109836 & 0.00395 & 0.6946695 \\
\hline extremo & 79 & 46433 & 277 & 109828 & 0.001682 & 0.6745624 \\
\hline posibilidades & 68 & 46444 & 241 & 109864 & 0.002731 & 0.6674323 \\
\hline satisfacción & 63 & 46449 & 251 & 109854 & 0.0001213 & 0.5936188 \\
\hline pensamiento & 76 & 46436 & 317 & 109788 & $4.01 \mathrm{E}-06$ & 0.5668339 \\
\hline objeto & 146 & 46366 & 677 & 109428 & $3.93 \mathrm{E}-15$ & 0.5089729 \\
\hline favor & 64 & 46448 & 304 & 109801 & $6.58 \mathrm{E}-08$ & 0.4976768 \\
\hline pena & 118 & 46394 & 601 & 109504 & $2.20 \mathrm{E}-16$ & 0.463423 \\
\hline motivo & 73 & 46439 & 409 & 109696 & $1.21 \mathrm{E}-13$ & 0.4216087 \\
\hline merced & 53 & 46459 & 305 & 109800 & $5.72 \mathrm{E}-11$ & 0.4106869 \\
\hline suerte & 47 & 46465 & 281 & 109824 & $9.02 \mathrm{E}-11$ & 0.3953384 \\
\hline virtud & 62 & 46450 & 385 & 109720 & $5.17 \mathrm{E}-15$ & 0.380401 \\
\hline imposibilidad & 55 & 46457 & 381 & 109724 & $2.20 \mathrm{E}-16$ & 0.3409687 \\
\hline libertad & 62 & 46450 & 497 & 109608 & $2.20 \mathrm{E}-16$ & 0.2943408 \\
\hline cuidado & 69 & 46443 & 635 & 109470 & $2.20 \mathrm{E}-16$ & 0.2561048 \\
\hline necesidad & 328 & 46184 & 3108 & 106997 & $2.20 \mathrm{E}-16$ & 0.2444735 \\
\hline deseo & 261 & 46251 & 2755 & 107350 & $2.20 \mathrm{E}-16$ & 0.2198712 \\
\hline gusto & 64 & 46448 & 721 & 109384 & $2.20 \mathrm{E}-16$ & 0.2090309 \\
\hline propósito & 73 & 46439 & 911 & 109194 & $2.20 \mathrm{E}-16$ & 0.1884099 \\
\hline deseos & 60 & 46452 & 753 & 109352 & $2.20 \mathrm{E}-16$ & 0.1875696 \\
\hline intención & 71 & 46441 & 933 & 109172 & $2.20 \mathrm{E}-16$ & 0.1788841 \\
\hline derecho & 49 & 46463 & 1160 & 108945 & $2.20 \mathrm{E}-16$ & 0.09904605 \\
\hline
\end{tabular}


La agrupación de la Tabla 3 se ha hecho siguiendo los valores incluidos en la columna titulada or de mayor a menor. Estas cifras corresponden a la razón de probabilidades (Odds Ratio en inglés), un valor que el programa estadístico R computa automáticamente para acompañar al valor de probabilidades (valor p) del Test Exacto de Fisher-Yates (TEFY), la base del análisis distintivo de colexemas de Gries \& Stefanowitsch (2004). ${ }^{6}$ Tanto el TEFy (y su valor p) como el valor de or se calcula teniendo en cuenta cuatro valores de frecuencia: 1) la frecuencia de un nombre dado en la construcción A; 2) la frecuencia de la construcción A con otros sustantivos; 3) la frecuencia del nombre en la construcción B; 4) la frecuencia de la construcción в con otros sustantivos. Estos son los valores que se presentan en las primeras cuatro columnas de las Tablas 3 y 5 , aunque para el TEFY no se calculan linealmente sino constituyendo una tabla de $2 \times 2$, según se ilustra en la Tabla 4 .

La idea del análisis distintivo de colexemas es que es más verosímil no comparar simplemente la frecuencia de uso de un sustantivo, como idea, en dos construcciones, sino considerar también la frecuencia global de ambas construcciones y tener esta en cuenta a la hora de interpretar el hecho de que idea ocurra 788 veces con de que y 925 veces con un com-

${ }^{6}$ Al clasificar los sustantivos según el valor de or en lugar de usar el valor p del TEFY, discrepo del modelo de Gries \& Stefanowitsch (2004). Sin embargo, el valor p es, en realidad, poco apropiado para medir el grado o la fuerza de asociación entre un colexema y una construcción, ya que solo indica la probabilidad de que la distribución de los cuatro valores de frecuencia en la tabla $2 \times 2$ se deba, o no, al azar. El valor de or, en cambio, sí puede considerarse un índice directo de este grado de asociación, y además es (relativamente) fácil de interpretar (cf. Schmid \& Küchenhoff 2013). 
Tabla 4. Frecuencias del sustantivo español idea con los dos tipos de completivas, de que e infinitivo

\begin{tabular}{lll}
\hline & de que & de + infinitivo \\
idea & 788 & 925 \\
ᄀidea & 45724 & 109180 \\
Total & 46512 & 110105 \\
\hline
\end{tabular}

El valor $\mathrm{p}$ del TEFY es prácticamente cero $(\mathrm{p}<0.001)$, mientras que el valor de or es de 2.03. ${ }^{7}$

plemento infinitivo. Aunque idea se usa 137 veces más (un 17\%) en la construcción $\mathrm{N} d e+$ infinitivo que en la construcción $\mathrm{N}$ de que, cuando se tiene en cuenta que la construcción con infinitivo es más de dos veces más frecuente que la construcción con completiva finita, esta diferencia pierde su importancia. Así, el valor de or de idea es de 2.03, lo que indica que la probabilidad de encontrar idea junto con una completiva finita es dos veces mayor que la de encontrarlo con un infinitivo, pese a que su frecuencia de uso con de + infinitivo es mayor.

Técnicamente, el valor de oR puede interpretarse como la razón entre dos probabilidades, la de encontrar un sustantivo determinado en una construcción comparado con la probabilidad de encontrarlo en otra (cf. Schmid \& Küchenhoff 2013). Valores por encima de uno (oR > 1) en las Tablas 3 y 5 indican que la probabilidad es mayor de encontrar el sustantivo con un complemento finito mientras que valores por debajo

7 Al usar la línea de comandos en $\mathrm{R}, 2.2 \mathrm{e}-16$ es el valor más reducido que arroja el programa. 
de uno $(\mathrm{oR}<1)$ indican que la probabilidad es mayor de que al sustantivo le siga un complemento infinitivo. Ahora bien, el límite de uno es, en sí, poco informativo. En este trabajo he agrupado los sustantivos según el valor de or sea o bien superior a dos $(\mathrm{OR}>2)$ o bien inferior a 0.5 . Con valores más extremos que estos dos, la preferencia por uno $u$ otro tipo de completiva tiene una probabilidad de al menos 2:1, mientras que con valores entre 0.5 y 2 la preferencia por una u otra construcción es tan reducida que parece difícil hablar de tal.

Según los datos de la Tabla 3, noticia es el sustantivo español que más fuertemente se asocia con los complementos finitos, con un valor de oR de 7.13, mientras que derecho, que tiene un valor de or de 0.1 -lo que supone una relación de 1:10 en contra de la variante finita ${ }^{8}$ - es el sustantivo que con mayor probabilidad se construye con completivas en infinitivo.

${ }^{8}$ El valor de 0.10 puede convertirse en una razón de probabilidades de 10:1, dividiendo 1 por 0.1 . Del mismo modo, un valor de or de 0.25 se convierte en una preferencia de 4:1 por los complementos infinitivos. 
Tabla 5. Los 37 sustantivos del portugués sometidos al análisis distintivo de colexemas

\begin{tabular}{|c|c|c|c|c|c|c|}
\hline $\begin{array}{l}\text { NÚMEROS } \\
\text { TOTALES }\end{array}$ & 20619 & & 52414 & & & \\
\hline LEX & $\mathrm{N}$ de que & $\neg \mathrm{N}$ de que & $\mathrm{N}$ de infinitivo & $\neg \mathrm{N}$ de infinitivo & TEFY $\mathrm{p}$ & OR \\
\hline certeza & 792 & 19827 & 142 & 52272 & $2.20 \mathrm{E}-16$ & 14.71006 \\
\hline noticia & 192 & 20427 & 43 & 52371 & $2.20 \mathrm{E}-16$ & 11.4472 \\
\hline suspeitas & 33 & 20586 & 8 & 52406 & $5.46 \mathrm{E}-12$ & 10.50054 \\
\hline suspeita & 78 & 20541 & 22 & 52392 & $2.20 \mathrm{E}-16$ & 9.042559 \\
\hline impressão & 318 & 20301 & 112 & 52302 & $2.20 \mathrm{E}-16$ & 7.314166 \\
\hline sinais & 55 & 20564 & 23 & 52391 & $1.19 \mathrm{E}-14$ & 6.091368 \\
\hline conta & 138 & 20481 & 61 & 52353 & $2.20 \mathrm{E}-16$ & 5.782677 \\
\hline expectativa & 65 & 20554 & 29 & 52385 & $2.26 \mathrm{E}-16$ & 5.712357 \\
\hline sinal & 188 & 20431 & 85 & 52329 & $2.20 \mathrm{E}-16$ & 5.664756 \\
\hline ilusão & 47 & 20572 & 28 & 52386 & $5.78 \mathrm{E}-10$ & 4.27431 \\
\hline diferença & 34 & 20585 & 29 & 52385 & $1.78 \mathrm{E}-05$ & 2.983523 \\
\hline espera & 69 & 20550 & 65 & 52349 & $2.05 \mathrm{E}-08$ & 2.70412 \\
\hline sensação & 111 & 20508 & 105 & 52309 & $9.83 \mathrm{E}-13$ & 2.696376 \\
\hline sentimento & 38 & 20581 & 36 & 52378 & $2.68 \mathrm{E}-05$ & 2.686317 \\
\hline ideia & 752 & 19867 & 803 & 51611 & $2.20 \mathrm{E}-16$ & 2.432811 \\
\hline fato & 324 & 20295 & 385 & 52029 & $2.20 \mathrm{E}-16$ & 2.15747 \\
\hline promessa & 57 & 20562 & 69 & 52345 & $6.02 \mathrm{E}-05$ & 2.103016 \\
\hline receio & 146 & 20473 & 209 & 52205 & $1.69 \mathrm{E}-07$ & 1.781231 \\
\hline culpa & 27 & 20592 & 41 & 52373 & 0.04261 & 1.674886 \\
\hline hipótese & 77 & 20542 & 143 & 52271 & 0.02939 & 1.370158 \\
\hline condição & 42 & 20577 & 86 & 52328 & 0.2793 & 1.241983 \\
\hline facto* & 446 & 20173 & 857 & 51557 & 0.05594 & 1.126498 \\
\hline pretexto & 65 & 20554 & 173 & 52241 & 0.8287 & 0.9549716 \\
\hline temor & 29 & 20590 & 82 & 52332 & 0.6739 & 0.8988692 \\
\hline esperança & 169 & 20450 & 481 & 51933 & 0.2203 & 0.892264 \\
\hline
\end{tabular}




\begin{tabular}{lllllll}
\hline $\begin{array}{l}\text { NúMEROS } \\
\text { TOTALES }\end{array}$ & 20619 & \multicolumn{5}{c}{52414} \\
LEX & $\mathrm{N}$ de que & $\neg \mathrm{N}$ de que & $\mathrm{N}$ de infinitivo & $\neg \mathrm{N}$ de infinitivo & TEFY p & OR \\
\hline esperanças & 33 & 20586 & 99 & 52315 & 0.4401 & 0.8471035 \\
causa & 41 & 20578 & 150 & 52264 & 0.03654 & 0.6942428 \\
razão & 69 & 20550 & 296 & 52118 & $4.27 \mathrm{E}-05$ & 0.5911908 \\
medo & 138 & 20481 & 627 & 51787 & $6.39 \mathrm{E}-11$ & 0.5565232 \\
perigo & 31 & 20588 & 145 & 52269 & 0.001375 & 0.5427791 \\
fim & 284 & 20335 & 1453 & 50961 & $2.20 \mathrm{E}-16$ & 0.4898354 \\
caso & 43 & 20576 & 283 & 52131 & $1.28 \mathrm{E}-10$ & 0.3849848 \\
sentido & 78 & 20541 & 574 & 51840 & $2.20 \mathrm{E}-16$ & 0.3429765 \\
facto & 55 & 20564 & 472 & 51942 & $2.20 \mathrm{E}-16$ & 0.2943086 \\
questão & 33 & 20586 & 338 & 52076 & $2.20 \mathrm{E}-16$ & 0.2469702 \\
possibilidade & 53 & 20566 & 679 & 51735 & $2.20 \mathrm{E}-16$ & 0.1963497 \\
pena & 21 & 20598 & 271 & 52143 & $2.20 \mathrm{E}-16$ & 0.1961608 \\
desejo & 37 & 20582 & 938 & 51476 & $2.20 \mathrm{E}-16$ & 0.09865518 \\
necessidade & 30 & 20589 & 1289 & 51125 & $2.20 \mathrm{E}-16$ & 0.05779274 \\
\hline
\end{tabular}

La agrupación se ha realizado siguiendo los valores de la columna OR. La tabla incluye 39 líneas ya que aparte de guardar líneas separadas para facto y fato, también incluye una entrada para las frecuencias sumadas de estas variantes (marcada con asterisco).

En portugués, los datos de la Tabla 5 indican que los sustantivos que más estrechamente se asocian con los complementos finitos son certe$z a$, noticia y suspeitalsuspeitas, mientras que necessidade y desejo son los que más claramente prefieren el infinitivo. Cabe observar que los datos revelan que en portugués son muchos más los sustantivos que prefieren la completiva finita ( $\mathrm{N}$ de que) que en español, lo cual puede considerarse un resultado sorprendente. También son menos numerosos los 
sustantivos que prefieren los complementos de infinitivo. ${ }^{9}$ En cambio, en español hay más sustantivos que no presentan una preferencia consistente. Estas diferencias se resumen en la Tabla 6.

Tabla 6. Distribución de las diferentes preferencias en español y portugués

\begin{tabular}{lll}
\hline Preferencia & Español & Portugués \\
\hline $\mathrm{N}$ de que & $10 / 18 \%$ & $\mathbf{1 7} / \mathbf{4 4} \%$ \\
$\mathrm{~N}$ de + Inf. & $\mathbf{2 9 / 5 2 \%}$ & $13 / 33 \%$ \\
Ninguna & $17 / 30 \%$ & $9 / 23 \%$ \\
Suma & 56 & 39 \\
\hline
\end{tabular}

Ji cuadrado $=7.527, \mathrm{GdL}=2$, valor $\mathrm{p}=0.0027$.

Otro punto interesante con respecto a la comparación entre el español y el portugués es que hay 21 sustantivos que figuran en las muestras de ambas lenguas. Esto implica que más de la mitad de los sustantivos analizados del portugués se analizan también en español, lo cual indica que hay un paralelo considerable entre ambas lenguas en cuanto a los sustantivos analizados. Comparando las Tablas 3 y 5, la coincidencia léxica es mayor entre los sustantivos sin preferencia, que incluyen los sustantivos

9 Sin embargo, estas cifras tienen que relacionarse con las cifras presentadas en la Tabla 2 (arriba), pues la muestra combinada del portugués incluye 210 sustantivos que por su mera frecuencia de uso "prefieren" el infinitivo, frente a tan solo 66 que "prefieren" de que. Esto, evidentemente, significa que las completivas de infinitivo son mucho más frecuentes que las finitas en portugués. También, en español, las completivas de infinitivo son más frecuentes que las finitas en un nivel general. 
pretexto, temor, esperança, esperanças, causa, razão, medo y perigo (ocho en total) en ambas lenguas. En cambio, solo cuatro de los sustantivos que prefieren las completivas finitas (noticia, sinal, ideia y fato) y tres de los que prefieren el infinitivo (pena, desejo y necessidade) son los mismos. Finalmente, seis sustantivos más también se incluyen en las muestras de ambas lenguas, pero sus preferencias vacilantes no permiten agruparlos con los quince sustantivos mencionados anteriormente.

Para terminar, cabe hacer hincapié en que los resultados presentados hasta aquí se basan en los datos de CE y de CP en su totalidad, es decir, no toman en consideración la dimensión diacrónica. Esta dimensión adicional se analizará a continuación (\$4).

Sin embargo, antes de proseguir con el análisis diacrónico de los datos, cabe abrir un paréntesis sobre la metodología empleada y la delimitación de las muestras analizadas. Al basar el análisis simplemente en los sustantivos más frecuentes de ambos tipos de completiva, solo se incluyen los sustantivos que se construyen frecuentemente tanto con de que como con complementos infinitivos. Detenerse en estos sustantivos puede motivarse, evidentemente, por el hecho de que el objetivo es determinar si hay o no identidad funcional entre uno y otro tipo de completivas. Lo que interesa es analizar los sustantivos que se combinan con ambos tipos y que, posiblemente, experimenten un cambio en sus preferencias a lo largo del tiempo.

También hay que destacar que el haber identificado muchos sustantivos que solo se combinan con un tipo de complementos ya es un resultado importante. Recuérdese que, según la Tabla 2, arriba, en español hay 114 sustantivos que prefieren complementos infinitivos, y 76 que prefieren complementos finitos con de que. En portugués, 210 sustantivos 
prefieren complementos infinitivos, y 66, complementos finitos. Estas cifras suponen un claro indicio de que los dos tipos de completivas no son intercambiables para la gran mayoría de sustantivos. Así, el análisis diacrónico de las muestras finales que ocupará el resto de este trabajo supone detenerse en una subclase de sustantivos: los que son compatibles con ambos tipos de completivas. La idea es que, si pueden identificarse motivos para la diferenciación en las preferencias por uno u otro tipo de completivas en esta subclase, resulta razonable suponer que estos se aplicarán también a los sustantivos que no aceptan ambos tipos de completivas.

\section{ANÁLisis Distintivo DE COLEXEMAS DIACRÓNICO Y CONTRASTIVO DE LAS ORACIONES COMPLETIVAS EN ESPAÑOL Y PORTUGUÉS}

Limitadas las muestras a 56 sustantivos del español y 37/39 sustantivos del portugués, este apartado está dedicado a dar cuenta de su uso con ambos tipos de completivas a lo largo de los años. Cabe destacar inicialmente que todos los datos analizados están divididos en siglos, puesto que esta es la división que impone el corpus (CP y CE). También hay que tener en cuenta que los análisis se limitan a los siglos XVI a XX en español, y Xvil a xx en portugués, ya que las completivas finitas $\mathrm{N}$ de que apenas se documentan en ese formato en los siglos anteriores (cf. Granvik 2015: 366, Figura 1).

La pregunta básica que orienta el análisis diacrónico es si en el periodo analizado los sustantivos muestran siempre la misma preferencia o 
si puede observarse un cambio en su combinación con los dos tipos de completivas. Sobre la base de las observaciones teóricas del apartado $\$ 2$, se esperaría encontrar una preferencia sucesivamente mayor de los sustantivos de percepción, cognición y habla $(\mathrm{PCH})$ por las completivas finitas, mientras que los sustantivos modales, de voluntad e influencia deberían mostrar una mayor adherencia a los complementos de infinitivo. Por otro lado, sobre la base de las preferencias que revelan los sustantivos en las muestras globales (apartado \$3), será interesante ver en qué medida los resultados del análisis diacrónico se corresponden con la situación global. Por ejemplo, ¿̨la mayor preferencia de estos sustantivos por la completiva finita siempre es mayor en portugués o esta se corresponde con una época en particular?

\subsection{Análisis diacrónico de los datos del portugués}

Empezando por el portugués, los resultados del análisis distintivo de colexemas (ADC) de los datos del CP correspondientes a los siglos XVII a xx se presentan en la Tabla 7. Esta tabla incluye 37 sustantivos (39 formas) y para cada siglo se indica si el sustantivo muestra una preferencia por un determinado tipo de completiva (de que o infinitivo) o si no presenta ninguna frecuencia. Esta clasificación se ha hecho siguiendo el valor de or que arroja el Test Exacto de Fisher-Yates (TEFY), tomando como límite la razón de probabilidades del 2:1, que corresponde a un valor de or por encima de dos o por debajo de 0.5 . 
Así, un sustantivo como certeza, que se encuentra en la parte superior de la tabla, tiene valores de or por encima de 2 en todos los siglos analizados. Por su parte, el último sustantivo de la tabla, necessidade, siempre presenta valores inferiores al 0.5. Finalmente, los valores de or de perigo, en la mitad de la tabla, siempre se encuentran entre 0.5 y 2 . La última columna de la Tabla 7 incluye los valores de or del análisis de toda la muestra, y los sustantivos están ordenados según este valor (es decir, se repite el mismo orden de la Tabla 5).

Tabla 7. Análisis distintivo de colexemas por siglos de los 37/39 sustantivos del portugués

\begin{tabular}{|c|c|c|c|c|c|}
\hline LEX & XVII & XVIII & XIX & $\mathrm{xx}$ & or global \\
\hline certeza & de que & de que & de que & de que & 14.71006 \\
\hline noticia & de que & de que & de que & de que & 11.4472 \\
\hline suspeitas & NA & de que & de que & de que & 10.50054 \\
\hline suspeita & de que & de que & de que & de que & 9.042559 \\
\hline impressão & NA & $\mathrm{NA}$ & ninguna & de que & 7.314166 \\
\hline sinais & de que & infinitivo & de que & de que & 6.091368 \\
\hline conta & infinitivo & de que & ninguna & de que & 5.782677 \\
\hline expectativa & NA & NA & infinitivo & de que & 5.712357 \\
\hline sinal & ninguna & de que & de que & de que & 5.664756 \\
\hline ilusão & NA & NA & de que & de que & 4.27431 \\
\hline diferença & infinitivo & de que & de que & de que & 2.983523 \\
\hline espera & infinitivo & NA & de que & de que & 2.70412 \\
\hline sensação & NA & NA & infinitivo & de que & 2.696376 \\
\hline sentimento & ninguna & infinitivo & de que & de que & 2.686317 \\
\hline ideia & $\mathrm{NA}$ & ninguna & de que & de que & 2.432811 \\
\hline
\end{tabular}




\begin{tabular}{|c|c|c|c|c|c|}
\hline LEX & XVII & XVIII & XIX & $x x$ & or global \\
\hline fato & NA & NA & infinitivo & de que & 2.15747 \\
\hline promessa & ninguna & de que & de que & de que & 2.103016 \\
\hline receio & ninguna & de que & de que & de que & 1.781231 \\
\hline culpa & de que & infinitivo & de que & ninguna & 1.674886 \\
\hline hipótese & NA & NA & de que & ninguna & 1.370158 \\
\hline condição & infinitivo & de que & de que & ninguna & 1.241983 \\
\hline facto $^{*}$ & NA & NA & ninguna & de que & 1.126498 \\
\hline pretexto & ninguna & infinitivo & ninguna & de que & 0.9549716 \\
\hline temor & de que & infinitivo & ninguna & de que & 0.8988692 \\
\hline esperança & infinitivo & ninguna & ninguna & de que & 0.892264 \\
\hline esperanças & de que & infinitivo & ninguna & de que & 0.8471035 \\
\hline causa & ninguna & de que & de que & ninguna & 0.6942428 \\
\hline razão & infinitivo & ninguna & ninguna & ninguna & 0.5911908 \\
\hline medo & infinitivo & de que & ninguna & ninguna & 0.5565232 \\
\hline perigo & ninguna & ninguna & ninguna & ninguna & 0.5427791 \\
\hline fim & ninguna & NA & ninguna & ninguna & 0.4898354 \\
\hline caso & ninguna & infinitivo & ninguna & infinitivo & 0.3849848 \\
\hline sentido & de que & infinitivo & infinitivo & infinitivo & 0.3429765 \\
\hline facto & NA & NA & ninguna & infinitivo & 0.2943086 \\
\hline questão & NA & infinitivo & ninguna & infinitivo & 0.2469702 \\
\hline possibilidade & infinitivo & NA & infinitivo & infinitivo & 0.1963497 \\
\hline pena & infinitivo & infinitivo & infinitivo & infinitivo & 0.1961608 \\
\hline desejo & infinitivo & ninguna & infinitivo & infinitivo & 0.09865518 \\
\hline necessidade & infinitivo & infinitivo & infinitivo & infinitivo & 0.05779274 \\
\hline $\mathrm{N}^{\text {os }}$ totales & $96 / 306$ & $84 / 248$ & 1363 / 3311 & $4000 / 7050$ & $5990 / 12534$ \\
\hline
\end{tabular}

La etiqueta NA indica la ausencia de casos en el siglo en cuestión. La preferencia marcada con tipo de letra rojo indica casos en los que la alternativa no se registra. 
Como se desprende de la Tabla 7, no se observa una coincidencia total entre el análisis global y el análisis por siglos. En cambio, se aprecia una considerable variación en las preferencias de los sustantivos entre un siglo y otro. En términos generales, esta variación se debe a que los datos de los siglos XVII y XVIII presentan una situación claramente diferente a la de los siglos XIX y xx, que demuestran preferencias muy afines a las globales. Esto, por su parte, es una consecuencia directa del hecho de que los casos de los siglos Xix y xx suponen el $90 \%$ (5363/5990) de los casos analizados.

Para empezar, en el siglo XviI hay 13 sustantivos que no se documentan en los datos (NA), y 6 casos en los que la alternativa no preferida no se documenta. En el XviII, 11 sustantivos carecen de ejemplos (NA) y 11 sustantivos más solo se documentan con un tipo de completiva. Es decir, aproximadamente el $25 \%$ de los sustantivos no se documentan con oración completiva antes de 1800 , y para otro $25 \%$ solo se documenta uno de los tipos de completiva. Una posible explicación es que el número de casos identificados en estos dos siglos es bastante reducido comparado con los dos siglos posteriores. Este es el caso especialmente de los complementos finitos cuyos números totales no llegan a los cien casos en el siglo XVII ni en el XVIII.

Segundo, considerando los 18 sustantivos que prefieren $\mathrm{N}$ de que en el nivel global, en los datos del siglo xvir solo cuatro de ellos (certeza, noticia, suspeita y sinais) muestran la misma preferencia. En el siglo XVIII la cifra se eleva un poco, y a los cuatro iniciales se añaden suspeitas, conta, sinal, diferença y promessa. En los siglos XIX y XX, en cambio, la coincidencia es casi total en comparación con la situación global. En el polo 
de los sustantivos que prefieren complementos de infinitivo, la diferencia entre los siglos XVII y XVIII con respecto a la situación global es menor. Sin embargo, con varios sustantivos se observa un cambio de preferencia a favor de las completivas finitas. Este es el caso de conta, diferença, espera y esperança que se combinan preferentemente con de que en el siglo $\mathrm{xx}$ tras haber preferido el infinitivo en el siglo xvII. Condição, razão y medo también se combinan más frecuentemente con el infinitivo en el siglo XVII, pero, aunque esta preferencia se pierde con el tiempo, estos sustantivos no acaban por decantarse a favor de $\mathrm{N}$ de que.

Tercero, existe un grupo de sustantivos que solo hacen su aparición en los datos del CP en el siglo XIx: impressão, expectativa, ilusão, sensação, idéia, hipótese, fato, facto, facto* Con la excepción de hipótese y facto, todos ellos acaban mostrando una preferencia por las completivas finitas (de que), si bien expectativa y sensação se documentan primero con el infinitivo (y en el siglo XIX solo se combinan con esta forma). Aunque estos constituyen ejemplos paradigmáticos de sustantivos encapsuladores en la lengua actual (Schmid 2000; Schmid \& Mantlik 2015), destaca uno sobre los demás, facto. Este es probablemente el sustantivo encapsulador más emblemático de todos (cf. Rodríguez Espiñeira 2015), pero, como revelan los datos, solo se documenta en portugués a partir del siglo XIX.

Un dato curioso con respecto a facto es que sus dos formas ortográficas, fato y facto no se comportan de la misma manera. Recuérdese que fato es la variante ortográfica empleada en el portugués brasileño, mientras que se prefiere la variante facto en el portugués europeo. Pues bien, según los datos de la Tabla 7, en el siglo xix fato se combina más frecuentemente con el infinitivo (87 casos frente a 9 de fato de que), mientras 
que facto con un valor de or de 1.8 no muestra preferencia alguna. ${ }^{10}$ En el siglo xx, en cambio, la variante europea facto se decanta claramente por el infinitivo, con un valor de or de 0.45 , mientras que la variante brasileña muestra una preferencia aun más clara por la completiva finita, con un valor de or por encima de 4. Esto puede relacionarse con la observación que hace Gärtner (1998: \$2.3.2.4.1.2) de que la construcción factiva con el infinitivo flexionado ( o facto de + infinitivo flexionado) es más frecuente y goza de un mayor uso que las oracionas factivas conjuntivas (o facto de que). En los datos analizados en este trabajo, el comentario de Gärtner parece verificarse solo en el portugués europeo, mientras que en Brasil la situación es muy diferente: allí la preferencia por la completiva finita es indudable. ${ }^{11}$

Finalmente, en un plano general lo que se observa en la Tabla 7 es un incremento diacrónico de la preferencia por las completivas finitas, mientras que son más los sustantivos que prefieren el infinitivo en los siglos XVII y XVIII que en el Xx. Esta tendencia creciente de combinarse con completivas finitas se aprecia en las cifras que se presentan en la Tabla 8. Aquí, el número de sustantivos que prefieren de que aumenta de 8 a 23 (de un 29\% al 59\%) entre el siglo xvir y el xx, mientras que los que prefieren el infinitivo bajan de 11 a 8 (del 39 al 21\%).

10 Hay 3 casos de facto de que y 7 de facto de + infinitivo, pero 3306 casos en total de $\mathrm{N}$ de que frente a 13843 casos de $\mathrm{N}$ de + infinitivo en el siglo xix, por lo que la asociación es mayor con de que que con el infinitivo.

11 Este contraste entre usos europeos y brasileños es lo que motiva que las cifras combinadas de ambas variantes ortográficas en facto $^{*}$ de la Tabla 6 indiquen que, en general, este sustantivo no muestra preferencia por ninguno de los dos tipos de completiva (el valor de or es de 1.28). 
Tabla 8. Distribución de las preferencias de los 37/39 sustantivos portugueses en los siglos $\mathrm{XVII}$ a $\mathrm{XX}$

\begin{tabular}{ccccc}
\hline PREFERENCIA & XVII & XVIII & XIX & XX \\
\hline de que & $8 / 29 \%$ & $12 / 41 \%$ & $17 / 44 \%$ & $23 / 59 \%$ \\
ninguna & $9 / 32 \%$ & $6 / 21 \%$ & $14 / 36 \%$ & $8 / 21 \%$ \\
infinitivo & $11 / 39 \%$ & $11 / 38 \%$ & $8 / 21 \%$ & $8 / 21 \%$ \\
Suma & 28 & 29 & 39 & 39 \\
\hline
\end{tabular}

Ji cuadrado $=9.75 . \mathrm{GdL}=6$. Valor $\mathrm{p}=0.1355$.

\subsection{Análisis diacrónico de los datos del español}

De modo semejante a lo que ocurre en portugués, la secuencia $\mathrm{N}$ de que en español no es indicio de una oración completiva de sustantivo hasta el siglo XVI, por lo que el análisis se limita a los siglos XVI a XX. Por otro lado, al contrario de lo que ocurre en portugués, en los resultados del espańol que se presentan en la Tabla 9 no se observa una gran diferencia entre los cinco siglos. Por ejemplo, la coincidencia en preferencias entre el siglo xvi y el xx es relativamente alta (de un $62 \%$, en total). ${ }^{12}$ Esto se debe, al menos en parte, a que la frecuencia de uso de los 56 sustantivos incluidos en el análisis es considerable ya en el siglo xVI, si bien va en aumento conforme se avanza en el tiempo (véanse los números totales de la última línea de la Tabla 9).

12 De los 16 sustantivos que se combinan preferentemente con de que en el siglo xvI, 11 muestran la misma preferencia en el xx. De los 21 sustantivos que prefieren el infinitivo en el siglo XVI, 12 mantienen esta preferencia. Así, 23 de un total de 37 sustantivos (= 62\%) muestran la misma preferencia en el xvi que en el xx. 
Tabla 9. Análisis distintivo de colexemas por siglos de los 56 sustantivos del español

\begin{tabular}{|c|c|c|c|c|c|c|}
\hline LEX & XVI & XVII & XVIII & XIX & $\mathrm{xx}$ & or global \\
\hline noticia & de que & de que & de que & de que & de que & 7.316939 \\
\hline seguridad & de que & de que & de que & de que & de que & 5.780432 \\
\hline$d u d a$ & de que & de que & de que & de que & de que & 4.777853 \\
\hline sentido & de que & de que & de que & de que & de que & 3.855983 \\
\hline$f e$ & de que & de que & de que & de que & de que & 3.833154 \\
\hline becho & de que & ninguna & ninguna & ninguna & de que & 3.759019 \\
\hline condición & de que & de que & de que & de que & de que & 3.320168 \\
\hline señal & de que & de que & de que & de que & de que & 3.060891 \\
\hline caso & de que & NA & ninguna & de que & de que & 2.073264 \\
\hline idea & de que & de que & ninguna & ninguna & de que & 2.034208 \\
\hline temor & ninguna & de que & de que & de que & de que & 1.844518 \\
\hline causa & ninguna & de que & de que & de que & de que & 1.614951 \\
\hline verdad & de que & de que & de que & de que & de que & 1.487653 \\
\hline esperanza & ninguna & ninguna & ninguna & ninguna & de que & 1.194697 \\
\hline promesa & ninguna & de que & ninguna & ninguna & ninguna & 1.129983 \\
\hline cargo & infinitivo & ninguna & de que & de que & infinitivo & 1.128656 \\
\hline señales & ninguna & de que & ninguna & ninguna & ninguna & 1.126083 \\
\hline pretexto & de que & ninguna & ninguna & ninguna & ninguna & 1.120614 \\
\hline circunstancia & infinitivo & de que & ninguna & ninguna & de que & 1.119383 \\
\hline miedo & infinitivo & de que & ninguna & de que & de que & 1.103513 \\
\hline fin & de que & ninguna & ninguna & ninguna & infinitivo & 1.045002 \\
\hline posibilidad & infinitivo & infinitivo & ninguna & ninguna & ninguna & 0.9459541 \\
\hline esperanzas & ninguna & ninguna & ninguna & ninguna & ninguna & 0.9402617 \\
\hline ventaja & ninguna & infinitivo & ninguna & ninguna & ninguna & 0.9112419 \\
\hline cuestión & de que & $\mathrm{NA}$ & de que & ninguna & ninguna & 0.8712148 \\
\hline consuelo & ninguna & ninguna & ninguna & ninguna & infinitivo & 0.8705351 \\
\hline riesgo & ninguna & ninguna & ninguna & ninguna & ninguna & 0.8438901 \\
\hline razón & infinitivo & ninguna & ninguna & de que & ninguna & 0.8413564 \\
\hline
\end{tabular}




\begin{tabular}{|c|c|c|c|c|c|c|}
\hline LEX & XVI & XVII & XVIII & XIX & $\mathrm{xx}$ & OR global \\
\hline palabra & ninguna & ninguna & ninguna & ninguna & de que & 0.8366489 \\
\hline términos & infinitivo & infinitivo & ninguna & de que & de que & 0.8283623 \\
\hline conveniencia & infinitivo & ninguna & infinitivo & ninguna & ninguna & 0.8204528 \\
\hline orden & ninguna & de que & ninguna & ninguna & infinitivo & 0.8103435 \\
\hline peligro & ninguna & ninguna & ninguna & ninguna & ninguna & 0.7856538 \\
\hline efecto & ninguna & ninguna & ninguna & ninguna & ninguna & 0.6946695 \\
\hline extremo & infinitivo & ninguna & infinitivo & ninguna & de que & 0.6745624 \\
\hline posibilidades & infinitivo & NA & NA & infinitivo & ninguna & 0.6674323 \\
\hline satisfacción & de que & de que & ninguna & infinitivo & ninguna & 0.5936188 \\
\hline pensamiento & infinitivo & ninguna & ninguna & ninguna & de que & 0.5668339 \\
\hline objeto & ninguna & de que & ninguna & ninguna & ninguna & 0.5089729 \\
\hline favor & de que & ninguna & infinitivo & infinitivo & ninguna & 0.4976768 \\
\hline pena & ninguna & ninguna & ninguna & infinitivo & infinitivo & 0.463423 \\
\hline motivo & ninguna & ninguna & infinitivo & infinitivo & ninguna & 0.4216087 \\
\hline merced & ninguna & infinitivo & infinitivo & ninguna & NA & 0.4106869 \\
\hline suerte & infinitivo & infinitivo & infinitivo & infinitivo & ninguna & 0.3953384 \\
\hline virtud & infinitivo & ninguna & infinitivo & infinitivo & ninguna & 0.380401 \\
\hline imposibilidad & ninguna & infinitivo & ninguna & infinitivo & infinitivo & 0.3409687 \\
\hline libertad & infinitivo & ninguna & infinitivo & infinitivo & infinitivo & 0.2943408 \\
\hline cuidado & infinitivo & infinitivo & infinitivo & infinitivo & ninguna & 0.2561048 \\
\hline necesidad & infinitivo & infinitivo & infinitivo & infinitivo & infinitivo & 0.2444735 \\
\hline deseo & infinitivo & infinitivo & infinitivo & infinitivo & infinitivo & 0.2198712 \\
\hline gusto & infinitivo & infinitivo & infinitivo & infinitivo & infinitivo & 0.2090309 \\
\hline propósito & infinitivo & infinitivo & infinitivo & infinitivo & infinitivo & 0.1884099 \\
\hline deseos & infinitivo & infinitivo & infinitivo & infinitivo & infinitivo & 0.1875696 \\
\hline intención & infinitivo & infinitivo & infinitivo & infinitivo & infinitivo & 0.1788841 \\
\hline derecho & infinitivo & infinitivo & infinitivo & infinitivo & infinitivo & 0.09904605 \\
\hline ocasión & ninguna & infinitivo & infinitivo & infinitivo & infinitivo & 0.2299782 \\
\hline $\mathrm{N}^{\mathrm{os}}$ totales & $1073 / 5086$ & $1190 / 3420$ & $2043 / 5235$ & $4359 / 10725$ & $4096 / 7564$ & $13360 / 33495$ \\
\hline
\end{tabular}

La etiqueta NA indica la ausencia de casos en el siglo en cuestión. La preferencia marcada con tipo de letra rojo indica casos en los que la alternativa no se registra. 
En la Tabla 9 se observa que las zonas coloreadas con naranja (de que) y morado (infinitivo) se mantienen prácticamente intactas a lo largo de los cinco siglos. Solo se aprecia un leve aumento de las preferencias por la completiva finita. Por ejemplo, los sustantivos posibilidad, razón y conveniencia prefieren el infinitivo en los primeros siglos, pero no en el $\mathrm{xx}$, mientras que temor, causa y esperanza parecen moverse hacia una mayor preferencia por las completivas finitas con de que. Sin embargo, como revelan las cifras de la Tabla 10, este aumento es poco consistente y relativamente modesto, ${ }^{13}$ de modo que, en un plano general, parece haber menos cambios en el español entre los siglos xvi y xx que en portugués.

Tabla 10. Distribución de las preferencias de los 56 sustantivos del español en los siglos XVI a Xx

\begin{tabular}{llllll}
\hline PREFERENCIA & XVI & XVII & XVIII & XIX & xx \\
\hline de que & $16 / 29 \%$ & $18 / 34 \%$ & $12 / 22 \%$ & $15 / 27 \%$ & $20 / 36 \%$ \\
ninguna & $19 / 34 \%$ & $20 / 38 \%$ & $26 / 47 \%$ & $23 / 41 \%$ & $20 / 36 \%$ \\
infinitivo & $21 / 38 \%$ & $15 / 28 \%$ & $17 / 31 \%$ & $18 / 32 \%$ & $15 / 27 \%$ \\
Suma & 56 & 53 & 55 & 56 & 55 \\
\hline \multicolumn{5}{r}{ Ji cuadrado $=5.14 . \mathrm{GdL}=8$. Valor $\mathrm{p}=0.74}$.
\end{tabular}

Ahora bien, si se enfoca la parte intermedia de la Tabla 9, donde el fondo blanco está moteado de colores, se puede observar bastante variación en los sustantivos individuales. En primer lugar, son pocos los

13 Lo indica también el hecho de que, con un valor p del 0.74, las cifras de la Tabla 10 están lejos de ser significativos. 
sustantivos que no presentan ninguna preferencia de modo sostenido: este grupo solo incluye los sustantivos esperanzas, consuelo, riesgo, efecto y peligro. En segundo lugar, sustantivos como esperanza, miedo, palabra, términos, extremo y pensamiento se mueven hacia el lado de los que prefieren completivas finitas. En tercer lugar, están los sustantivos fin, orden y pena que se mueven hacia una mayor preferencia por los complementos de infinitivo. Finalmente, destacan sustantivos como posibilidad, señales, satisfacción, motivo, merced y virtud que se caracterizan por una considerable alternancia diacrónica entre ambos tipos de completivas. Posibilidad, por ejemplo, empieza combinándose únicamente con infinitivos, pero a partir del siglo XVIII se construye también con de que. Aunque esta construcción va haciéndose cada vez más frecuente, nunca llega a ser la preferida. Así, los nueve casos de posibilidad de que en el XVIII, los 43 en el xIX y los 382 en el xx deben compararse con 30, 151 y 884 casos con infinitivo. ${ }^{14}$

14 En este punto cabe recordar que en el estudio de Granvik (2015: 372) posibilidad es el sustantivo español que más estrechamente se asocia con la construcción $\mathrm{N}$ de que en el análisis colostruccional basado en todo el CE. Por otra parte, también se asocia estrechamente con la construcción N de + infinitivo (cf. Granvik 2015: 383). Así, frente al análisis colostruccional empleado por Granvik (2015), el análisis distintivo de colexemas que contrasta dos construcciones, además de confirmar que posibilidad es uno de los sustantivos que más alterna entre ambas construcciones, revela que su uso en la variante $\mathrm{N}$ de que es más reciente que su uso con infinitivo. 


\subsection{Comparación de los resultados del análisis distintivo de colexemas diacrónico}

Resumiendo los resultados más importantes del análisis de las dos lenguas, cabe empezar por constatar que, con respecto a los sustantivos analizados, la preferencia por las completivas finitas es mayor en portugués que en español. Observando la distribución de la Tabla 11, esta diferencia parece deberse a que en español el número de sustantivos que no presenta ninguna preferencia es mucho mayor que en portugués. Las cifras corresponden al número total de cada tipo de preferencia (de que, ninguna e infinitivo), y se han calculado sobre la base de las Tablas 7 y 9. Esta situación la retrata también la Figura 1 (abajo), que reproduce las Tablas 7 y 9 en formato reducido, visualizando solo los diferentes cuadros colorados.

Tabla 11. Números y distribución de los tres grupos de sustantivos en español y portugués

\begin{tabular}{lll}
\hline Preferencia & Español & Portugués \\
\hline de que & $81 / 29 \%$ & $\mathbf{6 4} / \mathbf{4 6} \%$ \\
ninguna & $\mathbf{1 0 8 / 3 9 \%}$ & $37 / 27 \%$ \\
de + infinitivo & $86 / 31 \%$ & $38 / 27 \%$ \\
Suma & 275 & 139 \\
\hline
\end{tabular}

Ji cuadrado $=11.95, \mathrm{GdL}=2$, valor $\mathrm{p}=0.0025$. 

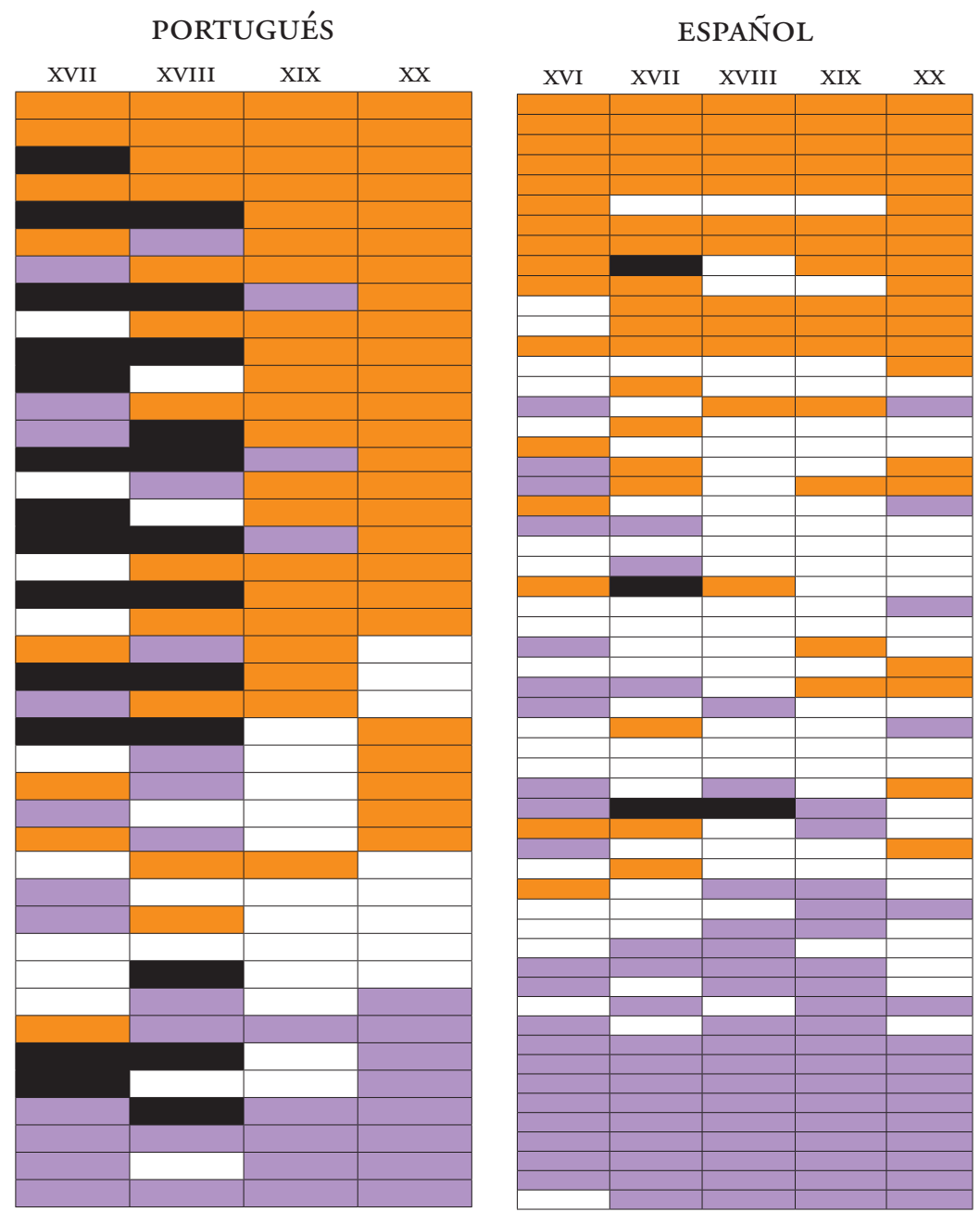

\section{Figura 1. Ilustración gráfica de las preferencias de los sustantivos del portugués y del español}

Los recuadros de color naranja hacen referencia a sustantivos que prefieren las completivas finitas, los morados hacen referencia a los que prefieren el infinitivo, los blancos a los que no muestran ninguna preferencia y los negros a la ausencia de casos. Los números de los primeros tres tipos de recuadro aparecen en la Tabla 10. 
Teniendo en cuenta la existencia del infinitivo flexionado en portugués, el que el portugués presente una mayor preferencia por las completivas finitas es quizá un resultado un poco sorprendente, pues se podría suponer que esta forma (cuyos datos se han incluido en la muestra como parte de los complementos de infinitivo) haría que la necesidad de recurrir a las completivas finitas fuera menor. Sin embargo, y este es un resultado importante, como podrá observarse en el apartado siguiente, el motivo principal para elegir uno u otro tipo de completiva no parece ser la existencia o ausencia de sujetos correferenciales en la oración principal y subordinada, sino que la elección parece deberse, más bien, a otros factores, como el tipo de sustantivo y, más importante aún, el sustantivo mismo.

Por otra parte, podría decirse que los datos del portugués reflejan, en realidad, la existencia de dos sistemas distintos. Así, si se observan tan solo los dos primeros siglos de la Figura 1, no se aprecia un predominio de las completivas finitas. De hecho, recordando las cifras presentadas en la Tabla 8, arriba, en los siglos XVII y XVIII son 20/57 los sustantivos que prefieren de que y 22 los que prefieren el infinitivo. En los siglos XIX y xx, las cifras son de 44/82 ( $\mathrm{N}$ de que) frente a 16/82 ( $\mathrm{N}$ de + infinitivo), así que la mayor preferencia por las completivas finitas corresponde a los últimos dos siglos. En español, no hay tal diferencia entre los primeros y los últimos siglos, si bien es verdad que en el siglo Xvi se aprecia una frecuencia algo más elevada de los complementos de infinitivo $(21 / 56=38 \%)$.

El hecho de que haya una mayor preferencia por los complementos de infinitivo en los siglos XVI y XVII podría deberse a dos cosas: prime- 
ro, en las lenguas medievales, la construcción con completiva finita no se encontraba muy avanzada (cf. Bogard \& Company 1989). Así, en los primeros textos del espańol medieval (siglos XII y XIII) la variante $\mathrm{N}$ que (y los escasos casos que hay de $\mathrm{N}$ de que) se emplea principalmente para introducir complementos de predicados compuestos del tipo [V+ $\mathrm{N}+$ que], como dar/hacer señal que, tener/aver miedo que, etc. (cf. los ejemplos de Moreno de Alba 2009: 1392-1394; Granvik, en prensa, a; en prensa, b). Segundo, si la afirmación de Moreno de Alba (2009: 1399) de que "[e]n todos los textos son más frecuentes las OCN [oraciones completivas del nombre] de infinitivo que las que cuentan con verbo conjugado" es de fiar, los complementos de infinitivo pueden considerarse diacrónicamente anteriores a los de verbo finito. Los números totales de las completivas finitas y de infinitivo en las Tablas 7 y 9 indican que la porción relativa de de que frente al infinitivo aumenta continuamente al menos entre el siglo xvi y el xx.

Desde esta perspectiva, el movimiento hacia una preferencia cada vez mayor por las completivas finitas que se documenta para algunos de los sustantivos analizados puede caracterizarse como la extensión de una nueva construcción sintáctica. Sin embargo, los detalles de esta extensión, que no afecta a todos los sustantivos por igual, siguen reclamando una aclaración: ¿̨las clases semánticas de los sustantivos, la relación entre subjuntivo e infinitivo y la correferencialidad de sujetos ayudan a dar cuenta de los cambios en las preferencias?

Antes de pasar al análisis detallado de los contextos de uso de los sustantivos, cabe mencionar que parte de la explicación de las grandes diferencias entre el portugués y el español puede encontrarse también en los 
datos que arrojan los corpus. Como indica la Tabla 7, en portugués el número de casos de las completivas de sustantivo es muy reducido antes del siglo XIX, lo cual se refleja también en el gran número de agujeros negros en la parte del portugués de la Figura 1. En español, en cambio, la diferencia en número de casos es menor entre un siglo y otro. Además, la Figura 1 presenta menos agujeros negros en el lado derecho. Así, aunque en el estudio de Granvik (2015) se constata que el uso de la construcción $\mathrm{N}$ de que con función completiva se extiende en el siglo XvII en portugués, el verdadero aumento del uso de esta construcción solo parece darse en el XIX.

4.4. Más allá del análisis distintivo de colexemas: el uso contextual de los sustantivos

Para intentar encontrar una explicación a las preferencias de los sustantivos por los dos tipos de completivas, se han clasificado los sustantivos en cuatro tipos según sus preferencias de construcción. Para asignar los sustantivos a los tipos A, B y C se ha seguido un criterio relativamente estricto, es decir, solo se han incluido aquellos sustantivos que muestren valores de or por encima de 2 , entre 0.5 y $2, y$ por debajo de 0.5 en todos los siglos analizados. Finalmente, el tipo $D$ incluye sustantivos que muestran un cambio de su preferencia entre el siglo XVII y xx, o bien a favor de las completivas finitas o bien a favor del infinitivo. Los cuatro tipos y los sustantivos que incluyen son los siguientes: 
A) Los sustantivos que prefieren las completivas finitas ( $\mathrm{N}$ de que) (OR > 2):

ES: noticia, seguridad, duda, sentido, fe, condición, señal, verdad (8);

РТ: certeza, notícia, suspeita, suspeitas (4);

в) Los sustantivos que prefieren las completivas con infinitivo ( $\mathrm{N} d e+$ infinitivo) (or $<0.5)$ :

Es: ocasión, derecho, intención, deseos, propósito, gusto, deseo, necesi$\operatorname{dad}(8)$;

PT: necessidade, pena, desejo, possibilidade (4);

c) Los sustantivos que no tienen ninguna preferencia (Ninguna) (or entre 0.5 y 2):

Es: esperanzas, riesgo, peligro, efecto (4);

PT: perigo, fim (2);

D) Los sustantivos cuyas preferencias alternan a lo largo del tiempo.

I. Pasan a preferir de que:

ES: esperanza, miedo, palabra, términos, extremo, pensamiento (6); РТ: facto, sentido, caso, causa РТ: conta, fato, esperança, esperanças (4);
2. Pasan a preferir el infinitivo:

Es: fin, orden, pena (3); (4).

Según esta agrupación, el objeto del análisis contextual y semántico lo constituyen 29 sustantivos del español y 18 sustantivos del portugués. De estos, 14 sustantivos del español y 8 del portugués se asocian preferentemente con las completivas finitas (grupos A + DI), mientras 
que 11 sustantivos del español y 8 del portugués se asocian con el infinitivo (grupos A + D2). Finalmente, cuatro sustantivos del español y dos del portugués no muestran apenas preferencias por uno u otro tipo de completivas (tipo c). En lo siguiente, se examinará la influencia de las clases semánticas, la correferencialidad de sujetos y el modo de la subordinada sobre cada uno de estos cuatro tipos de sustantivos. En la primera fase del análisis, se prestará atención a los tipos A, в у c. En la segunda fase, se compararán los resultados de estos tres grupos con los sustantivos del grupo D.

Para el análisis semántico he utilizado la clasificación semántica de Schmid (2000: 294-297), ${ }^{15}$ quien divide los sustantivos encapsuladores del inglés en seis clases. Sin embargo, en los datos que manejo solo se identifican sustantivos factuales, mentales, lingüísticos y modales, por lo que las Tablas 12a y 12b demuestran la distribución de los sustantivos del español y del portugués sobre estas cuatro clases. Como se constató en la parte teórica (apartado $\$ 2$ ), donde no hay correspondencia entre la clasificación de Schmid y la de Givón (2001) es en el caso de los sustantivos factuales. Sin embargo, como indica la Tabla 12a, estos no son muy numerosos, y en portugués no hay ningún sustantivo factual en los grupos A, в у с (Tabla 12b). De los cuatro sustantivos factuales del espanol, sentido y verdad pueden considerarse relativamente neutros, mien-

15 Para asignar los sustantivos a cada una las cuatro clases semánticas, me he guiado por los valores más patentes semánticamente en los contextos de uso concretos extraídos de los corpus. Por ejemplo, el sustantivo sentido en español se usa típicamente como parte de la locución conjuntiva en el sentido de que con valor de 'con el significado', motivo por el cual se ha clasificado como factual. 
tras que efecto presenta matices causales y señal se acerca a los sustantivos lingüísticos con función ilocutiva.

Tabla 12a. Distribución de las clases semánticas por los grupos A, в y C en español

\begin{tabular}{llll}
\hline & \multicolumn{3}{c}{ Preferencia } \\
\hline Clase semántica & A. de que & B. infinitivo & C. ninguna \\
factuales & $\mathbf{3}$ (sentido, señal, verdad) & 0 & 1 (efecto) \\
lingüisticos & $\mathbf{1}$ (noticia) & 0 & 0 \\
mentales & 2 (duda, fe) & 4 (deseo, deseos, gusto, propósito) & 1 (esperanzas) \\
modales & 2 (condición, seguridad) & $\mathbf{4}$ (derecho, intención, necesidad, & 2 (peligro, riesgo) \\
Suma & 8 & 8 & 4 \\
\hline
\end{tabular}

Tabla 12b. Distribución de las clases semánticas por los grupos A, в y C en portugués

\begin{tabular}{llll}
\hline & \multicolumn{3}{c}{ Preferencia } \\
\hline Clase semántica & A. de que & B. infinitivo & c. ninguna \\
factuales & 0 & 0 & 0 \\
lingüísticos & 1 (notícia) & 0 & 0 \\
mentales & 3 (certeza, suspeita, suspeitas) & 2 (desejo, pena) & $1($ fim) \\
modales & 0 & 2 (necessidade, possibilidade) & 1 (perigo) \\
Suma & 4 & 4 & 2 \\
\hline
\end{tabular}

Como revelan las cifras, hay una clara diferencia semántica entre los sustantivos que prefieren completivas finitas ( $\mathrm{N}$ de que) y los que prefieren el infinitivo. Aunque el número de casos es demasiado reducido para permitir la verificación estadística, la tendencia parece evidente. Tanto en español como en portugués los sustantivos lingüísticos se combinan 
preferentemente con completivas finitas, y en español lo mismo ocurre con los factuales. En cambio, los sustantivos de significado modal se combinan típicamente con completivas de infinitivo, mientras que los sustantivos mentales son los que menos se asocian con un tipo de completiva determinado.

Observando los sustantivos que representan las diferentes clases semánticas, es notable el paralelo con las observaciones de Hernanz (1999) y la NGLE con respecto a la diferencia entre complementos finitos y de infinitivo. Por ejemplo, la mayoría de los sustantivos modales que se construyen preferentemente con infinitivo se asocian claramente a los predicados de voluntad e influencia, es decir, con la modalidad subjuntiva. En cambio, los sustantivos lingüísticos noticialnotícia se corresponden con los predicados de PCH de Givón (2001), se asocian con el indicativo y prefieren completivas finitas. Lo mismo ocurre con los sustantivos factuales (en español), sentido, señal y verdad. Estos prefieren siempre las completivas finitas, hacen referencia a hechos objetivos y se asocian, por ende, con la modalidad indicativa.

Hay, sin embargo, dos sustantivos que van en contra de esta tendencia, a saber, condición y seguridad, que prefieren completivas finitas aunque han sido clasificados como modales. En el caso de condición, la explicación de esta preferencia no esperada posiblemente reside en el hecho de que en la gran mayoría de los casos se usa como parte la conjunción condicional a condición de que. Por un lado, el hecho de formar parte de una locución conjuntiva significa que el significado léxico del sustantivo condición probablemente se encuentra parcialmente atenuado. Por otro, podría argumentarse que dentro del esquema de oraciones condiciona- 
les [si A, B], una cláusula finita supone una condición más fuerte en comparación con el infinitivo en relación con el apódosis, que suele ser una oración finita. Ya que las oraciones condicionales incluyen siempre una oposición entre dos situaciones, expresar la prótasis en forma de cláusula finita (aunque sea en subjuntivo) supone un contrapeso al apódosis conceptualmente más anclado en el universo (hipotético) del hablante que una cláusula de infinitivo (cf. Silva 2008; Langacker 2008a). Este contraste semántico entre verbos finitos e infinitivos podría explicar por qué el formato conjuntivo (a condición de que...) es más frecuente que el formato preposicional (a condición de + infinitivo).

Con respecto al sustantivo seguridad, aunque su modalidad epistémica parece incuestionable, el uso de este sustantivo en español guarda un estrecho parentesco con los predicados mentales de creencia (creencia, conocimiento sensación...). Por este mismo motivo, seguridad igual que su homólogo adjetival, seguro, se asocian más bien con la modalidad indicativa. Y ello, por su parte, es un factor que se asocia con la preferencia por completivas finitas.

Los sustantivos clasificados como mentales, por su parte, constituyen un grupo relativamente heterogéneo. Así, una parte de los sustantivos mentales prefieren completivas finitas, mientras que otros prefieren el infinitivo o no tienen ninguna preferencia. Este diferente comportamiento de unos y otros sustantivos mentales parece deberse a que los sustantivos mentales se dividen en dos grupos, volitivos y emotivos, por un lado, y conceptuales y de creencia, por otro (cf. Schmid 2000: 295296). Los del primer grupo se construyen típicamente con subjuntivo en espańol, mientras que los del segundo se combinan con indicativo. 
Así, los sustantivos mentales que prefieren completivas finitas, duda y $f e$ en español, y certeza, duda, suspeita y suspeitas en portugués, se asocian más bien con la modalidad indicativa que subjuntiva. Esto puede verse en los ejemplos (4a-b):

(4) a. Los que son amigos de medicinarse, están en fe de que los purgantes sólo arrancan del cuerpo los humores viciosos: (CE, Teatro crítico universal, XVIII)

b. Tudo estava bem assim. Não sabia exactamente porquê, mas tinha a certeza de que tudo estava bem. (CP, Ventura: Vergonha, $\mathrm{xx}$ )

(5) a. ¿qué importa? Tendrás el gusto de que te cuelgen y que nos cuelguen á todos. (CE, Don Felipe el Prudente, XIx)

b. Já há algumas semanas, membros de aquela distrital a manifestaram o desejo de que Nobre Guedes encabece a lista. (CP, 19N:Pt:Público, xx)

En cambio, los sustantivos mentales que prefieren las completivas en infinitivo, como deseo(s), desejo, gusto y pena, pueden caracterizarse como volitivos y emotivos, y se asocian más con el modo subjuntivo que con el indicativo (ejemplos 5a-b).

La relación entre los sustantivos de los grupos а у в (16 en español y 8 en portugués) y la modalidad en la variante $\mathrm{N}$ de que se ilustra numéricamente en la Tabla 13. En consonancia con la hipótesis, los sustantivos que prefieren la variante finita (es decir, noticia, seguridad, duda, sentido, fe, condición, señal y verdad en español; certeza, notícia, suspeita y suspeitas en portugués) tienen el predicado en indicativo en el $82 \%$ de los 
casos en los que se combinan con una completiva finita. Para los sustantivos que prefieren complementos de infinitivo, las cifras son más claras todavía, y se encuentra al modo subjuntivo en el $95 \%$ de los casos con completiva finita.

Tabla 13. Distribución de los modos subjuntivo e indicativo con los sustantivos que prefieren las completivas finitas (de que, tipo a) y los que prefieren complementos de infinitivo (tipo в) en español y portugués

\begin{tabular}{llll}
\hline PREFEREnCia & SUbjuntivo & INDicativo & Suma \\
\hline A. de que & $44 / 18 \%$ & $195 / 82 \%$ & 239 \\
B. infinitivo & $222 / 95 \%$ & $12 / 5 \%$ & 234 \\
Suma & 266 & 207 & 473 \\
\hline
\end{tabular}

Ji cuadrado $=277.78, \mathrm{GdL}=1$, valor $\mathrm{p}<0.001$.

Entre las excepciones a estas tendencias clarísimas se encuentran, en portugués, los sustantivos suspeita y suspeitas que se combinan frecuentemente (en un $35 \%$, aproximadamente) con subjuntivo aunque prefieren de que. En español ya se ha mencionado el caso de condición, que, pese a construirse preferentemente con completivas finitas, rige subjuntivo. También señal se usa frecuentemente con el subjuntivo, especialmente cuando tiene función directiva, como ocurre en el ejemplo (6). En el lado de los sustantivos que prefieren los complementos de infinitivo pero que se combinan también con indicativo, el caso más llamativo es el de propósito (ejemplo 7), que en la locución a propósito de (que) adquiere un significado cercano a 'en relación a/con', 'con respecto a', y en este uso se combina con el verbo en indicativo. Sin embargo, esta función relacional de propósito solo supone un $25 \%$ de su uso contextual. 
(6) Munuza mueve la cabeza irritado en señal de que se vayan (CE, Obras dramáticas, XIX)

(7) Bueno, todo esto era a propósito de que no sé por qué la persona que grabó antes dijo... (CE, Habla Culta: Santiago, Xx)

Como indican estos ejemplos, la excepcionalidad parece ser una consecuencia de diferencias semánticas entre distintos usos de los mismos sustantivos. Esto quiere decir que la hipótesis de la importancia de la asociación con modalidades diferentes no se ve invalidada por estas aparentes excepciones. Parece tratase más bien de que la estructura semántica de las palabras a veces tiene que considerarse en un nivel más detallado, reconociendo su carácter polisémico y el efecto que la polisemia puede tener sobre la selección de modo.

El último aspecto por el que tradicionalmente se distinguen los complementos finitos de los de infinitivo es por la correferencialidad de sujetos entre la cláusula principal y la subordinada. ${ }^{16}$ Según Moreno de Alba (2009: 1391), “cuando el sujeto de la oración es diferente del sujeto de la oración regente, en la que está incrustado el sustantivo al que modifica o completa la ocN, entonces el verbo de la completiva aparece no en infinitivo sino en forma conjugada". Aunque podría considerarse que la idea de sujetos correferenciales no tiene la misma relevancia al tratarse de núcleos nominales que cuando el núcleo de la cláusula principal es un verbo, este aspecto es importante para diferenciar los sustantivos que prefieren completivas finitas (tipo A) de los demás tipos (B y C).

16 En realidad, más que sujetos correferentes se trata de que algún actante, tema, paciente, de la oración principal se retenga para que actúe como sujeto del predicado de la subordinada (cf. Moreno de Alba 2009: 1387). 
Como revelan las cifras de las Tablas $14 \mathrm{a}$ y $14 \mathrm{~b}$, con sujetos no correferenciales las completivas finitas suponen la inmensa mayoría, tanto en español como en portugués. Esta tendencia se verifica por igual con los tres tipos de sustantivos (A. los que prefieren de que, в. los que prefieren el infinitivo y c. los que no prefieren ni de que ni el infinitivo).

Tabla 14a. Distribución de sujetos correferenciales y no correferenciales en los tres tipos de sustantivos del español

\begin{tabular}{lllll}
\hline Preferencia & Construcción & Correferenciales & No correferenciales & Nro. total \\
\hline \multirow{2}{*}{ A. de que } & de que & $15 \%$ & $85 \%$ & 140 \\
& infinitivo & $52 \%$ & $48 \%$ & 154 \\
\multirow{3}{*}{ B. Infinitivo } & de que & $3 \%$ & $97 \%$ & 138 \\
& infinitivo & $79 \%$ & $21 \%$ & 140 \\
\multirow{3}{*}{ C. Ninguna } & de que & $6 \%$ & $94 \%$ & 100 \\
& infinitivo & $69 \%$ & $31 \%$ & 100 \\
\hline
\end{tabular}

Construcción $\mathrm{N}$ de que. Ji cuadrado $=14.394, \mathrm{GdL}=2$, valor $\mathrm{p}=0.000749$. Construcción $\mathrm{N}$ de infinitivo. Ji cuadrado $=24.961, \mathrm{GdL}=2$, valor $\mathrm{p}=3.801 \mathrm{e}-06$.

\section{Tabla 14b. Distribución de sujetos correferenciales y no correferenciales en los tres tipos de sustantivos del portugués}

\begin{tabular}{lllll}
\hline Preferencia & Construcción & Correferenciales & No Correferenciales & Nro. total \\
\hline \multirow{2}{*}{ A. de que } & de que & $14 \%$ & $86 \%$ & 80 \\
& infinitivo & $70 \%$ & $30 \%$ & 63 \\
\multirow{3}{*}{ B. Infinitivo } & de que & $5 \%$ & $95 \%$ & 76 \\
\cline { 2 - 5 } c. Ninguna & infinitivo & $73 \%$ & $28 \%$ & 80 \\
& de que & $10 \%$ & $90 \%$ & 31 \\
& infinitivo & $88 \%$ & $13 \%$ & 40 \\
\hline
\end{tabular}

Preferencia $\mathrm{N}$ de que. Ji cuadrado $=3.2271, \mathrm{GdL}=2$, valor $\mathrm{p}=0.1992$. Preferencia $\mathrm{N}$ de infinitivo. Ji cuadrado $=4.4761, \mathrm{GdL}=2$, valor $\mathrm{p}=0.1067$. 
Sin embargo, las cifras del grupo a de la Tabla 14a indican que, en español, con estos sustantivos (que prefieren de que) el infinitivo se usa con casi la misma frecuencia con sujetos no correferenciales que con sujetos correferenciales (un 52\% frente al $48 \%$ ). De modo semejante, los sustantivos del tipo A también se combinan con completiva finita con sujetos correferenciales en mayor medida que los otros tipos. Esta diferencia es mayor en español (un $15 \%$ frente al $3 \%$ y el $6 \%$ ) que en portugués (14\% frente al $5 \%$ y el $10 \%$ ).

Estos resultados, que se verifican en los valores p significativos de la Tabla 14a frente a los valores no significativos de la Tabla 14b, parecen indicar que en español los sustantivos del tipo a (que prefieren de que) constituyen un grupo diferente de los demás. Para estos sustantivos, la construcción con completiva finita es una alternativa viable aun cuando hay correferencialidad de sujetos. Teniendo en cuenta que el tipo A lo ejemplifican sustantivos como noticia, seguridad, duda y certeza, que se corresponden semánticamente con los verbos $\mathrm{PCH}$, no es sorprendente que las oraciones completivas se construyan con verbo conjugado, pues esto es lo que se observa también para muchos de estos verbos: pienso que soy un hombre sincero, estoy seguro de que iré al partido, etc.

Por otra parte, cuando los sujetos no son correferenciales, lo que es la norma para los sustantivos del tipo A, también el infinitivo parece ser una alternativa, aunque este uso es más frecuente en los siglos anteriores al xx en español. Las combinaciones de sustantivos del tipo A con sujetos no correferenciales con infinitivo y correferenciales con verbo conjugado se ejemplifican en (8) a (11). 


\section{Español}

Sujeto no correferencial con infinitivo:

(8) a. Debemos decirnos aquí, siempre que veamos construir edificios público o tengamos noticia de consumarse operaciones financieras. (CE, Horas de lucha, XIx)

b. constaba que el Brasil había impuesto como un soborno la condición de rebelarse a un jefe de provincia, (CE, Campaña en el Ejército Grande, XIX)

Sujeto correferencial con de que:

(9) a. Eurídice suspira, canta, suspende, y admira y libre la sacarás, en fe de que estima más a tu pluma que a su lira. (CE, Poesía. Selección, XVI)

b. Señor Constancio, emperador; y aunque fuesen en principio válidos, lo serían a condición de que no degenerasen, como fatalmente degeneran, en contratos de esclavitud. (CE, Último día del paganismo y..., XIx)

\section{Portugués}

Sujeto no correferencial con infinitivo:

(10) Duas horas depois, por toda a vila e extramuros de Guimaraes grassava a notícia de ter fugido Teresinha, a rica e linda herdeira da Rua dos Fomos (CP, 18:Branco:Viúva) 
Sujeto correferencial con de que:

(11) Quem, senão vós mesma, restituída aos seus braços, lhe dará a certeza de que estais salva das mãos dos infiéis? (CP, 18:Herculano:Eurico)

Como indican los ejemplos (8) y (10), en los casos de infinitivos con sujetos no correferenciales la construcción en español es muy semejante a la del portugués: el sujeto no correferencial es un sN que acompańa al infinitivo. Así, en este punto la diferencia entre las dos lenguas no parece encontrarse en la construcción en sí, sino más bien en la frecuencia de uso del infinitivo con sujeto no correferencial tras sustantivos que, típicamente, prefieren completivas finitas, como noticia, duda, sentido, condición y señal. Y esta frecuencia es más elevada en español que en portugués (un 48 frente a un $30 \%$ en las Tablas 14a y 14b).

En cambio, los casos de (9a-b), por un lado, y (11), por otro, ejemplifican estructuras diferentes: en español los sustantivos forman parte de dos locuciones conjuntivas (en fe de que y a condición de que), mientras que en portugués el sustantivo certeza tiene un uso más independiente (en 11 se usa como complemento directo del verbo ditransitivo dar). Esta parece ser una diferencia significativa entre las dos lenguas, pues de los ocho sustantivos que prefieren la completiva finita en español (grupo A), al menos cuatro forman muy a menudo parte de expresiones fijadas: en el sentido de que, en fe de que, a condición de que, (es) señal de que, algo que no se observa para ninguno de los cuatro sustantivos del portugués: certeza, notícia, suspeita, suspeitas. 
En portugués, los sustantivos homólogos sentido, condição y sinal se incluyen también en el análisis (cf. Tablas 5 y 7): sentido prefiere completivas infinitivas, condição no tiene preferencias y sinal prefiere completivas finitas, pero no en la medida suficiente para incluirse en la muestra final que se analiza en este apartado. Observando más de cerca el uso de estos sustantivos, tanto condição como sentido se emplean también como parte de locuciones prepositivas/conjuntivas, pero en los datos del CP la construcción con infinitivo es claramente más frecuente que la construcción con completiva finita. ${ }^{17}$ Estas diferencias sugieren que quizá el infinitivo flexionado influencie la preferencia de construcción en el caso de las locuciones prepositivas/conjuntivas, si bien el determinar si esto constituye algo más que una hipótesis basada en unas pocas observaciones tendrá que dejarse para investigaciones futuras.

Para terminar, cabe incorporar los sustantivos que experimentan un cambio en sus preferencias en el análisis. Están, por un lado, los sustantivos del grupo DI que cambian a favor de de que y, por otro, los del grupo D2 que cambian a favor del infinitivo.

Con respecto a la clasificación semántica, en comparación con los grupos A у в, los sustantivos de los grupos D I (cambio a favor de de que) y D2 (cambio a favor del infinitivo), tanto confirman cuanto contradicen las observaciones anteriores. Las cifras de la distribución semántica se presentan en la Tabla 15. Así, por ejemplo, entre los seis sustantivos espańoles del grupo Di (> de que) hay uno factual (extremo), dos lingüísticos

17 Los datos son: com a condição de que (30 casos) vs. ter condição de + infinitivo. $(67+7)$; (no) sentido de que (74 casos) vs. sentido de + infinitivo (533 + 18 casos). 
(palabra, términos) y tres mentales (esperanza, miedo, pensamiento). En portugués la situación es semejante: un sustantivo factual ( fato), uno lingüístico (conta) y dos mentales (esperança, esperanças) pasan a la esfera de las completivas finitas. Estas cifras significan que la tendencia observada anteriormente de que hay una asociación entre la preferencia por completivas finitas (de que) y los sustantivos lingüísticos y factuales ( $\mathrm{PCH}$ ), se ve reforzada.

Tabla 15. Clases semánticas de los sustantivos de los grupos D I y D2

\begin{tabular}{|c|c|c|c|c|}
\hline \multirow{2}{*}{\multicolumn{2}{|c|}{ CLASE SEMÁNTICA ESPAÑOL }} & \multirow{3}{*}{$\begin{array}{l}\text { > de que } \\
\text { PORTUGUÉs } \\
1 \text { (fato) }\end{array}$} & \multicolumn{2}{|c|}{ D2. CAMBIO $>$ infinitivo } \\
\hline & & & \multirow{2}{*}{$\begin{array}{l}\text { ESPAÑOL } \\
0\end{array}$} & \multirow{2}{*}{$\begin{array}{l}\text { PORTUGUÉs } \\
4 \text { (caso, causa } \\
\text { facto, sentido) }\end{array}$} \\
\hline Factuales & 1 (extremo) & & & \\
\hline Lingüísticos & 2 (palabra, términos) & 1 (conta) & 1 (orden) & 0 \\
\hline Mentales & $\begin{array}{l}3 \text { (esperanza, miedo, } \\
\text { pensamiento) }\end{array}$ & $\begin{array}{l}2 \text { (esperança, } \\
\text { esperanças) }\end{array}$ & $2($ fin, pena $)$ & 0 \\
\hline (Modales) & 0 & 0 & 0 & 0 \\
\hline Suma & 6 & 4 & 3 & 4 \\
\hline
\end{tabular}

En cambio, entre los tres sustantivos españoles del grupo D2 (>infinitivo) se encuentra un sustantivo lingüístico (orden), lo que va contra la tendencia anteriormente mencionada. Pero orden es un sustantivo de fuerza ilocutiva directiva (semejante a los predicados de influencia de Givón), que se combina con subjuntivo, así que en este caso parece que la asociación con la modalidad subjuntiva es más fuerte que la clase semántica de los sustantivos de lengua. En portugués, por su parte, los cuatro sustantivos que pasan a preferir la completiva de infinitivo se han clasi- 
ficado como factuales (caso, causa, facto, sentido), y esto también va en contra de la tendencia observada anteriormente con respecto al español, donde los sustantivos factuales preferían construirse con completivas finitas. Ahora bien, estos cuatro sustantivos factuales se usan, en una considerable medida, como parte de locuciones prepositivas que rigen un complemento infinitivo: no caso de + infinitivo (60\%), no sentido de (90\%), pelo facto de (40\%) y por causa de (90\%). Parece posible, aunque esté lejos de probarse, que este hecho tenga que ver con su preferencia por los complementos de infinitivo, si bien esto implica una preferencia contraria a la que se observó para el español, donde a condición de que prefiere complementos finitos.

Por último, resulta llamativo que la mitad de los sustantivos que cambian a favor de de que sean mentales (tres en español y dos en portugués), pues esta clase se encuentra bastante dividida también en las Tablas 12a y 12b. Además, de estos cinco sustantivos solo uno, pensamiento, se asocia claramente con el modo indicativo. Al mismo tiempo, hay dos sustantivos mentales que cambian a favor de la completiva de infinitivo, fin y pena. Estos, sin embargo, se asocian con la modalidad subjuntiva (son sustantivos volitivos y de emoción, respectivamente), por lo que el que se asocien con completivas de infinitivo no es una sorpresa. En cambio, el análisis contextual de los usos de miedo y esperanza y esperança y esperanças, no revela ninguna pista de por qué empiezan a combinarse más frecuentemente con las completivas finitas, una vez que ambos se asocian con el modo subjuntivo.

En suma, el análisis de las clases semánticas de los sustantivos cuyas preferencias experimentan un cambio diacrónico corrobora en parte los 
resultados de los sustantivos de los tipos а у в: entre los sustantivos que pasan a preferir de que hay varios que son lingüísticos y factuales. Pero también hay que añadir la clase de los sustantivos mentales que no presentan un comportamiento uniforme. Algunos de estos pasan a preferir las completivas finitas (miedo y esperanza del español y esperança(s) del portugués), mientras que otros acaban favoreciendo las completivas de infinitivo ( fin y pena del espańol). En muchos de estos casos la asociación con el modo indicativo o subjuntivo es importante para entender la preferencia, pero también hay algunos donde ni la asociación con el modo ni la correferencialidad de sujetos, ni aun la construcción sintáctica en que se insertan, ayudan a dar cuenta del cambio. Todo esto significa que la clase de los sustantivos mentales no supone un buen indicador de las preferencias de tipo de completiva.

Observando la dimensión del modo con más detalle, las cifras de la Tabla 16 indican que los sustantivos de los tipos Di (cambio a favor de de que) y D2 (cambio a favor del infinitivo) funcionan esencialmente del mismo modo que los de los tipos а у в. Es decir, los sustantivos que cambian a favor de de que (DI) se combinan preferentemente con completivas finitas con el verbo en indicativo, mientras que los que cambian a favor del infinitivo (D2) lo hacen con el verbo en subjuntivo. 
Tabla 16. Comparación de los sustantivos del tipo A y D I, y в y D2, respectivamente y su combinación con el modo subjuntivo e indicativo en las completivas finitas en español y portugués

\begin{tabular}{llll|llll}
\hline Español & SUbJUntivo & INDicativo & SUma & Portugués & SUbJUntivo & Indicativo & SUma \\
\hline Tipo A & $18 \%$ & $82 \%$ & 159 & Tipo A & $19 \%$ & $81 \%$ & 80 \\
Tipo D I & $38 \%$ & $62 \%$ & 120 & Tipo D I & $35 \%$ & $65 \%$ & 80 \\
Ji cuadrado $=3.73, \mathrm{GdL}=1, \mathrm{p}<0.001$. & Ji cuadrado $=4.58, \mathrm{GdL}=1, \mathrm{p}=0.033$. \\
Tipo в & $95 \%$ & $5 \%$ & 158 & Tipo в & $95 \%$ & $5 \%$ & 76 \\
Tipo D2 & $95 \%$ & $5 \%$ & 60 & Tipo D2 & $43 \%$ & $57 \%$ & 74 \\
Ji cuadrado $=3.2356 \mathrm{e}-30, \mathrm{GdL}=1, \mathrm{p}=1$. & Ji cuadrado $=44.37, \mathrm{GdL}=1, \mathrm{p}<0.001$. \\
\hline
\end{tabular}

Como puede observarse, aunque la tendencia es la misma para los sustantivos del tipo A y D I, por un lado, y B y D2, por otro, la relación con el modo es más fuerte para los sustantivos de los tipos a y в que para los de los tipos DI y D2. Comparando las dos lenguas, se observa que los sustantivos que prefieren de que (tipos A y DI) se comportan de modo muy semejante en español y en portugués. Aunque hay una diferencia cuantitativa entre los sustantivos del tipo A y del tipo D I, siempre es más frecuente el uso del indicativo en la completiva finita.

Con respecto a los sustantivos que prefieren el infinitivo (tipos B y D2), en cambio, las dos lenguas no se comportan del mismo modo. Mientras que en español la relación con el modo subjuntivo es clarísima para ambos tipos de sustantivos (de ahí el valor p de 1 en esa parte de la tabla), en portugués los sustantivos que experimentan un cambio a favor de las completivas de infinitivo (D2) se combinan más frecuentemente con completivas finitas con el verbo en indicativo que con el verbo en 
subjuntivo. Esto contrasta claramente con lo que ocurre con los sustantivos del tipo в en portugués.

Este comportamiento discrepante es resultado de dos sustantivos en concreto, facto y sentido que no se construyen con subjuntivo en esta lengua. En este punto cabe recordar que la variante brasileña del sustantivo factual por excelencia, fato, prefiere completivas finitas, un comportamiento que es más consonante con la tendencia generalmente observada de que los sustantivos que prefieren de que se construyen con el verbo subordinado en indicativo. ${ }^{18}$ Aquí, la excepción la constituye la forma facto del portugués europeo, que prefiere construirse con infinitivo.

Lo que indican estos resultados es que los sustantivos que cambian de preferencia de construcción (tipos DI y D2) no funcionan de modo idéntico a los sustantivos que "siempre" prefieren uno u otro tipo de completiva (los tipos а у в). Por otra parte, si lo que ocurre es que los dos tipos de completivas atraen nuevos sustantivos a su esfera de influencia, es natural que estos presenten usos contextuales diferentes.

Finalmente, con respecto a la correferencialidad, los sustantivos que cambian de preferencias (tipos D I y D2) se construyen con sujetos correferenciales y no correferenciales de modo muy semejante a como lo hacen los tipos а у в, por lo que no he considerado relevante presentar los datos detallados. Baste con decir que, en ambas lenguas y para ambos tipos (D I y D2), entre el 70 y el $90 \%$ de los sujetos son no correferenciales

$18 \mathrm{Al}$ contrario de lo que ocurre en español, en portugués la expresión o fatolfacto de que no se combina con subjuntivo en más del $90 \%$ de los casos. 
cuando la completiva es finita. Con sujetos correferenciales se usa el infinitivo en un mínimo de un 78 y en un máximo del $98 \%$ de los casos.

En resumen, como ilustran los ejemplos presentados y la discusión de los resultados de las Tablas 12 a 16, tanto las clases semánticas de los sustantivos como la correferencialidad de sujeto y la selección de modo son importantes a la hora de explicar las preferencias de los diferentes sustantivos por uno u otro tipo de completiva. Pero también hay excepciones, que revelan que algunas clases de sustantivos no constituyen grupos homogéneos. Los sustantivos tampoco funcionan de modo idéntico a los verbos al constituir el predicado núcleo de una oración completiva, aunque no cabe negar que los tres tipos de predicados (verbales) de Givón son importantes para los sustantivos.

Un caso llamativo de comportamiento idiosincrásico lo constituye el sustantivo condición en español: este se usa típicamente como parte de la locución conjuntiva a condición de que, que se construye con subjuntivo a pesar de preferir completivas finitas. Por otra parte, el sustantivo propósito, que prefiere completivas infinitivas, presenta dos usos diferentes: cuando tiene el significado de 'relación' se combina típicamente con indicativo, cuando tiene el significado de 'objetivo' típicamente rige subordinadas con el verbo en subjuntivo. En portugués, cabe destacar las preferencias opuestas de las formas facto y fato: la variante brasileña fato se comporta como cabría esperar de un sustantivo que se combina preferentemente con el indicativo: prefiere las completivas con de que. Pero su homólogo del portugués europeo prefiere las completivas de infinitivo, y se combina frecuentemente con el infinitivo (flexionado) aun con sujetos no correferenciales. 
Lo que indica todo esto es, por un lado, que las clasificaciones semánticas rara vez logran captar todas las características semánticas relevantes de sus miembros. En el caso de los sustantivos abstractos, hay que recordar además que algunos de ellos son claramente polisémicos, mientras que casi todos pueden presentar matices semánticos distintos según su contexto de uso. Por otro, también destaca que, más allá de las clases y tipos de sustantivos, en algunos casos la construcción gramatical en la que se insertan los sustantivos puede influir en la preferencia de completiva; otras veces, son los mismos sustantivos los mejores indicadores del tipo de completiva que se prefiere.

\section{Conclusiones}

En este trabajo he intentado responder a dos preguntas básicas. Por un lado, me interesaba determinar si desde la perspectiva de los diferentes sustantivos que se combinan con complementos oracionales puede considerarse que los dos tipos de oraciones completivas, las de verbo finito y las de infinitivo, funcionan de modo idéntico. Por otro lado, teniendo en cuenta la existencia de consideraciones teóricas que rechazan la identidad semántica entre el infinitivo y las oraciones finitas (cf. Langacker 2008a), me interesaba averiguar si las supuestas diferencias semánticas entre ambos tipos de completiva se manifestarían en distintas preferencias de construcción de los sustantivos individuales.

Una hipótesis inicial era que los sustantivos preferirían construirse con uno u otro tipo de completiva según su clase semántica. Pero en el 
análisis también se incluyeron dos aspectos adicionales que han ocupado un lugar destacado en la descripción de las oraciones completivas, a saber, la correferencialidad de sujetos (cf. Moreno de Alba 2009; Raposo et al. 2013) y el modo de la completiva (finita) (cf. Hernanz 1999; NGLE $\$ 26.11$ ).

Los resultados de los sucesivos análisis han destacado que los dos tipos de completivas son claramente distintos, y que la elección del tipo de completiva depende de cada uno de los tres aspectos considerados en el análisis. Ahora bien, mientras que la correferencialidad de sujetos es, en principio, un factor que permite mantener el argumento de la identidad funcional de los dos tipos de completivas -con sujetos correferenciales se usa el infinitivo, con un nuevo sujeto en la subordinada, se introduce que + verbo conjugado (cf. Moreno de Alba 2009)-, las clases semánticas de Schmid (2000) (sustantivos mentales, lingüísticos, factuales y modales) y los tipos de predicados de Givón (de percepción, cognición y habla - $\mathrm{PCH}-$ de influencia -manipulación- y modales), así como la compatibilidad con el modo subjuntivo o indicativo, son indicadores de una diferencia conceptual entre las completivas finitas e infinitivas.

Así, por ejemplo, si bien la mayoría de los sustantivos analizados son sensibles al factor de correferencialidad, de modo que su uso con el infinitivo está relacionado con sujetos correferenciales, también es posible encontrar casos en los que una completiva finita retoma el mismo sujeto de la oración principal. Esto se verifica con mayor frecuencia con sustantivos que prefieren la construcción finita (del tipo a), como fe, condición y señal en español, y certeza en portugués (cf. los ejemplos 9 y 11 arriba). 
Los sustantivos fe y certeza fueron clasificados como mentales, mientras que señal se ha considerado un sustantivo factual, y estas dos clases semánticas se asocian estrechamente con las completivas finitas, especialmente en español. En cambio, los sustantivos modales y los mentales de volición y emoción, como ocasión, deseo, gusto, necesidad, etc. se combinan preferentemente con completivas de infinitivo. Como señala Hernanz (1999), esta es una distinción conceptual, que se refleja en que hay una afinidad semántica entre determinados tipos de predicados (sean sustantivos, verbos o adjetivos) y uno u otro tipo de complemento. Conforme a esta distinción semántico-conceptual, el análisis reveló diferencias significativas en cuanto al modo de las oraciones subordinadas: los sustantivos que se combinan típicamente con completivas de infinitivo tienden a construirse con el verbo en subjuntivo cuando la completiva es finita. Con los sustantivos de cognición y habla ocurre lo contrario: prefieren las completivas finitas y en estas el verbo típicamente va en indicativo.

Cabe recordar en este punto que el análisis detallado del uso de los diferentes tipos de completivas se basa en muestras relativamente limitadas. Así, en realidad solo se han analizado los sustantivos que se construyen con suficiente frecuencia con ambos tipos de completivas. Sin embargo, las tendencias observadas para estos sustantivos parecen aplicarse también a los que en los corpus utilizados "solo" se combinan con el infinitivo o con completivas finitas. Por ejemplo, en una muestra de 20 sustantivos arbitrariamente escogidos de los 114 que solo se combinan con de que en el Corpus del español, y de otros 20 de los 200 que solo se combinan con de que en el Corpus do Português, 14 son lingüísticos o 
mentales (de tipo no volitivo ni emotivo). De otras dos muestras de 20 sustantivos que prefieren el infinitivo, 10 y 13, en espańol y portugués, respectivamente, son modales. Además, el hecho de que la mayor parte de los 362 y 402 sustantivos extraídos de los corpus prefieran, directamente, uno u otro tipo de completiva, en realidad constituye una prueba bastante evidente de que los dos tipos de completivas no son idénticos. Por otra parte, los sustantivos del tipo C, que no muestran ninguna preferencia por uno u otro tipo de completivas, también indican claramente que en ciertos casos ambos tipos de completivas son igualmente posibles.

En términos diacrónicos, el análisis también reveló algunos cambios relevantes. En primer lugar, el español presenta un panorama de oraciones completivas de sustantivos bastante más estable que el portugués. En esta lengua hay una gran diferencia entre las completivas que se documentan en el siglo XVII comparado con el xx. Conforme a esto, es también en portugués donde se observa un mayor movimiento hacia uno de los dos tipos de completivas. En los datos analizados del portugués, la variante finita se hace mucho más frecuente al llegar al siglo XIX, y sustantivos como conta, fato y esperança pasan a construirse preferentemente con de que en el siglo xx. En español también hay algunos sustantivos que evolucionan en este sentido, pero en general la diferencia entre el siglo XVI y el xx es menor que la que se observa en portugués.

Tras examinar la evolución entre 1500/1600 y 1999 de una muestra de los sustantivos más frecuente y típicamente usados en las secuencias $\mathrm{N}$ de que y $\mathrm{N}$ de + infinitivo en español y portugués, quedan varias cuestiones pendientes, de las que quiero destacar dos. La primera es ampliar el panorama con la época medieval, la segunda, examinar con mayor 
detalle la función discursiva-textual de los sustantivos y sus complementos. Para terminar, entonces, me aventuraré a avanzar algunas consideraciones de carácter general sobre las completivas de sustantivo. Estas van más allá de lo que permiten afirmar los datos presentados, pero espero que ilustren algunos aspectos importantes que considero merecedores de atención en el futuro.

Primero, si lo que revelan mis datos es un cambio diacrónico a favor de las completivas finitas a partir de la época clásica, cabría esperar que en los siglos anteriores a la introducción de la variante $\mathrm{N}$ de que, las completivas finitas (del formato $\mathrm{N} q u e$ ) fueran menos frecuentes todavía. Si esto es así -y la observación de Moreno de Alba (2009) de que el infinitivo es siempre más frecuente que los complementos finitos en sus datos sugiere que lo es- entonces la expansión de las completivas finitas puede considerarse un caso de innovación sintáctica. Teniendo en cuenta, además, que si en los primeros tiempos los complementos oracionales de sustantivo eran principalmente de tipo argumental, es decir, expresaban un argumento de un sustantivo deverbal, entonces la función clasificadora de los sustantivos que funcionan como núcleo de las oraciones completivas en la actualidad, supone otra innovación, esta vez de naturaleza semántico-funcional.

Desde esta perspectiva, el segundo aspecto que debería enfocarse en un estudio futuro es la función discursivo-textual de las completivas de sustantivo, para determinar hasta qué punto la función clasificadora depende de los sustantivos núcleo, y en qué medida el tipo de completiva influye en la relación entre el sustantivo y la completiva. Siguiendo a Givón (2001), cabría esperar que las completivas finitas favorecieran la 
función clasificadora, pues las oraciones de verbo finito son conceptualmente más autónomas, mientras que con el infinitivo se expresaría en mayor grado complementos argumentales, que se relacionan de modo más estrecho con el núcleo nominal. Tal repartición del trabajo podría explicar, en parte, la creciente frecuencia de uso de las completivas finitas frente al estancamiento de los complementos de infinitivo.

Evidentemente, la consideración tanto de los orígenes como del uso actual de las oraciones completivas de sustantivo supone una necesidad para la plena comprensión de la coexistencia de dos tipos de completivas, cuyos perfiles son claramente diferentes (como espero que el presente estudio haya conseguido ilustrar) a pesar de sus puntos en común.

\section{REFERENCIAS}

Bogard, Sergio \& Company Company, Concepción. 1989. Estructura y evolución de las oraciones completivas de sustantivo en el español. Romance Philology 43(2). 258-273.

Davies, Mark. 2002-. Corpus del español: 100 million words, 1200s-1900s. http://www.corpusdelespanol.org (Consultado el 11-01-2017.)

Davies, Mark \& Ferreira, Michael. 2006-. Corpus do Português: 45 million words, 1300s-1900s. http://www.corpusdoportugues.org (Consultado el 11-01-2017.)

Delbecque, Nicole. 1998. De la relación predicativa entre el nombre abstracto y la cláusula en la construcción 'GN de que + cláusula'. Lingüistica (ALFAL) 10. 69-103. 
Delbecque, Nicole. 2000. La estructura [el $\mathrm{N}_{\text {Aвsтracto }}$ de que + completiva]: variación formal y funcional. En Wotjak, Gerd (ed.), En torno al sustantivo y adjetivo en el español actual. Aspectos cognitivos, semánticos, (morfo) sintácticos y léxicogenéticos, 55-80. Frankfurt Am Main: Vervuert-Iberoamericana.

De Mello, George. 1998. Verbo de influencia + cláusula / infinitivo con sujetos no correferenciales. En Delbecque, Nicole \& de Paepe, Christian (eds.), Estudios en honor del profesor Josse De Kock, 177-184. Lovaina: Leuven University Press.

Escandell Vidal, María Victoria. 1995. Los complementos del nombre. Madrid: Arco/Libros.

Fernández Ramírez, Salvador. 1953[1986]. Gramática española. 3.1. El nombre. Madrid: Arco/Libros.

Fernández Lagunilla, Marina. 1992. Sobre los complementos de infinitivo con verbos de percepción: propuesta de revisión de unos datos históricos a la luz de una hipótesis sincrónica. En Ariza Viguera, Manuel \& Cano Aguilar, Rafael (eds.), Actas del II Congreso Internacional de Historia de la Lengua Española, vol. 1, 391-402. Madrid: Asociación de Historia de la Lengua Española.

Gärtner, Eberhard. 1998. Grammatik der portugiesischen Sprache. Tubinga: Max Niemeyer.

GDLE = Bosque, Ignacio \& Demonte, Violeta (eds.). 1999. Gramática descriptiva de la lengua española. 2 vols. Madrid: Espasa Calpe.

Girón Alconchel, José Luis. 2004. Cambios gramaticales en los Siglos de Oro. En Cano Aguilar, Rafael (ed.), Historia de la lengua española, 859-893. Barcelona: Ariel. 
Givón, Talmy. 2001. Syntax. An Introduction. 2 vols. Ámsterdam: John Benjamins.

Gries, Stefan \& Stefanowitsch, Anatol. 2004. Extending collostructional analysis: A corpus-based perspective on 'alternations'. International Journal of Corpus Linguistics 9(1). 97-129.

Granvik, Anton. 2015. Oraciones completivas de sustantivo: un análisis contrastivo en español y portugués. Verba 42. 347-401.

Granvik, Anton. (en prensa, a). Análisis histórico-comparativo de las oraciones completivas de sustantivo en español y portugués: nacimiento y evolución de una alternancia sintáctica. Neuphilologische Mitteilungen.

Granvik, Anton. (en prensa, b). Diacronía de la construcción encapsuladora en español: un análisis colostruccional y (un poco) más allá. Actas del X Congreso Internacional de Historia de la Lengua Española. Hernanz, Maria Lluïsa. 1999. El infinitivo. En Bosque, Ignacio \& Demonte, Violeta (eds.), Gramática descriptiva de la lengua española, vol. 2, 2197-2356. Madrid: Espasa Calpe.

Langacker, Ronald. W. 2008a. Cognitive grammar. A basic introduction. Oxford: Oxford University Press.

Langacker, Ronald. W. 2008b. Subordination in cognitive grammar. En Lewandowska-Tomaszczyk, Barbara (ed.), Asymmetric events, 137149. Ámsterdam: John Benjamins.

Leonetti, Manuel. 1993. Dos tipos de completivas en sintagmas nominales. Lingüistica 5. 1-36.

Leonetti, Manuel. 1999. La subordinación sustantiva: las subordinadas enunciativas en los complementos nominales. En Bosque, Ignacio \& 
Demonte, Violeta (eds.), Gramática descriptiva de la lengua española, vol. 2, 2083-2104. Madrid: Espasa Calpe.

Moreno de Alba, José G. 2009. Sintagmas completivos del nombre: complementos adnominales y oraciones completivas del nombre. En Company Company, Concepción (dir.), Sintaxis histórica de la lengua española. Segunda parte: La frase nominal. vol. 2, t. 2, 1321-1409. México: Fondo de Cultura Económica/Universidad Nacional Autónoma de México.

NGLE $=$ Real Academia Española \& Asociación de Academias de la Lengua Española. 2009. Nueva gramática de la lengua español. 2 vols. Madrid: Espasa.

Pountain, Christopher. 2014. Preposición + que en español. Cuadernos de Lingüistica de El Colegio de México 2. 9-54.

Raposo, Eduardo B. Paiva \& Bacelar do Nascimento, Maria Fernanda \& Coelho da Mota, Maria Antonia \& Segura, Luísa \& Mendes, Amália (eds.). 2013. Gramática do Portugués. 2 vols. Lisboa: Fundação Calouste Gulbenkian.

Rodríguez Espiñeira, María José. 2003. Sobre dos tipos de completivas en frases nominales. Verba 30. 163-202.

Rodríguez Espińeira, María José. 2010. Complementos en genitivo y lecturas diatéticas de los nominales de acción. Verba 37. 7-56.

Rodríguez Espiñeira, María José. 2015. El sustantivo 'hecho' como ejemplar de nombre encapsulador factual. En Studium Grammaticae. Homenaje al profesor José A. Martinez, 655-674. Oviedo: Universidad de Oviedo. Schmid, Hans-Joerg. 2000. English Abstract Nouns as Conceptual Shells. From Corpus to Cognition. Berlín: Mouton de Gruyter. 
Schmid, Hans-Jörg \& Küchenhoff, Helmut. 2013. Collostructional analysis and other ways of measuring lexicogrammatical attraction: Theoretical premises, practical problems and cognitive underpinnings. Cognitive Linguistics 24(3). 531-577.

Schmid, Hans-Joerg \& Mantlik, Anette. 2015. Entrenchment in historical corpora? Reconstructing dead authors' minds from their usage profiles. Anglia 133(4). 583-623.

Serradilla Castaño, Ana María. 1995. Sobre las primeras apariciones de construcciones preposicionales ante que completivo en español medieval. Factores determinantes. EPOS Revista de Filología 11. $147-163$.

Serradilla Castaño, Ana María. 2010. La subordinación completiva en español antiguo: continuidad y ruptura de los modelos latinos. En Castillo Lluch, Mónica \& López Izquierdo, Marta (eds.), Modelos latinos en la Castilla medieval, 145-158. Madrid: IberoamericanaVervuert.

Da Silva, Augusto Soares. 2008. The Portuguese inflected infinitive and its conceptual basis. En Lewandowska-Tomaszczyk, Barbara (ed.), Asymmetric events, 227-243. Ámsterdam: John Benjamins.

Tarr, Frederick Courtney. 1922. Prepositional complementary clauses in Spanish with special reference to the works of Pérez Galdós. Revue Hispanique 56. 1-264.

Vanderschueren, Clara \& Diependaele, Kevin. 2013. The Portuguese inflected infinitive: An empirical approach. Corpus Linguistics and Linguistic Theory 9(1). 161-186. 
Vanderschueren, Clara \& de Cuypere, Ludovic. 2014. The inflected/ non-inflected infinitive alternation in Portuguese adverbial clauses. A corpus analysis. Language Sciences 41. 153-174.

Vesterinen, Rainer. 2006 [2011]. Subordinação adverbial - um estudo cognitive sobre o infinitivo, o clitico SE e as formas verbais finitas em proposiçôes adverbiais do Português Europeu. Estocolmo: Stockholms universitet. (Tesis doctoral.) 